\title{
Reference levels of ecosystem indicators at multispecies maximum sustainable yield
}

\author{
Briton Florence ${ }^{1,}{ }^{*}$, Shannon Lynne ${ }^{2}$, Barrier Nicolas ${ }^{1}$, Verley Philippe ${ }^{1,3}$, Shin Yunne-Jai ${ }^{1,2}$
}

\author{
${ }^{1}$ Institut de Recherche pour le Développement, MARBEC (IRD, Univ Montpellier, Ifremer, CNRS), \\ Montpellier, France \\ 2 Department of Biological Sciences, and Marine Research Institute, Private Bag X3, Rondebosch, \\ South Africa \\ ${ }^{3}$ Institut de Recherche pour le Développement, UMR AMAP 123, Montpellier, France \\ *Corresponding author : Florence Briton, email address : florence.briton@ifremer.fr
}

\begin{abstract}
:
We investigate reference points for ecosystem indicators in support of an Ecosystem Approach to Fishery. In particular, we assess indicator capacity to detect when the Multispecies Maximum Sustainable Yield (MMSY) is reached, under a wide range of multispecies fishing strategies. The analysis was carried out using a simulation approach based on the ecosystem model OSMOSE in the southern Benguela. We show that the 13 ecosystem indicators have reference points at MMSY that are highly variable across fishing strategies. The state of the ecosystem at MMSY is so variable across fishing strategies that it is not possible to set reference points without considering the fishing strategy. However, strategy-specific reference points were found to constitute robust proxies for MMSY in more than $90 \%$ of the simulated fishing strategies. For instance, under the current fishing strategy in the southern Benguela, robust reference points at MMSY could be identified for the following indicators: mean length of fish, mean lifespan, biomass over catch ratio, trophic level of the surveys, mean trophic index, proportion of predatory fish, intrinsic vulnerability index, and mean maximum length.
\end{abstract}

Keywords: ecosystem-based fishery management, fishing strategy, indicator reference point, multispecies MSY, southern Benguela 


\section{Introduction}

\section{Ecological indicators for an Ecosystem Approach to Fisheries}

3

4

The early 2000's featured as a turning point in the way fisheries management should be considered. The limits of the dominant single-species approach opened the way to the concept of a more integrative Ecosystem Approach to Fisheries (EAF or EBFM- Ecosystem Based Fisheries Management) (Marasco et al. 2007: Ruckelshaus et al. 2008). Most importantly, EBFM embodies a desire to reconcile sometimes contradictory expectations from society regarding the ecosystem and the services it provides. EBFM also aims at moving beyond mono-specific approaches to fisheries. Some species cannot be evaluated or managed independently from others (by-catches, trophic interactions, competition for habitats), hence the necessity to establish management policies at the scale of an ecosystem rather than of a stock (Hall and Mainprize, 2004; Shannon et al. 2004; Mackinson et al., 2009). Finally, the transition towards an ecosystem approach to fisheries is particularly crucial as the mono-specific approach can be too lenient when applied to multiple species in parallel, potentially leading to the collapse of certain stocks (Ghosh and Kar, 2013: Voss et al., 2014).

To make progress in the implementation of EBFM, the status of the ecosystem needs to be assessed and its key properties characterized (e.g. resilience, biodiversity, structure or functioning). Numerous ecosystem indicators were developed to provide relevant information on the health of an ecosystem, commonly defined in terms of preserving the following 4 attributes: (1) biodiversity, (2) stability and resilience, (3) structure and functioning, and (4) the productive potential (Shin et al. 2010b). Aside from giving insight into the state of an ecosystem, an indicator should fulfil various criteria suggested by Rice and Rochet (2005): namely a suitable candidate indicator should (1) have ecological meaning regarding a perturbation, (2) be sensitive to such perturbation, (3) be easily measurable, and (4) be widely understood by non-experts. Many indicators were proposed at the onset of the EAF worldwide, and eventually the 
time came to evaluate their usefulness and performance and select the ones best meeting the afore-mentioned requirements (Shin et al., 2012; Coll et al., 2016; Shin et al., 2018).

Values and trends of indicators are intended not only to assess the state of an ecosystem, but also how far it is from reaching one or several objectives. This can be accomplished by means of reference points. A reference point for an indicator may either be a value one aims at reaching (which will be referred to as a "target" reference point) or a threshold that should not be crossed (referred to as "limit" or "precautionary" reference points) (Jennings and Dulvy, 2005). Target reference points may be more suitable if one aims at maximizing the yield for instance, whereas limit reference points may be more closely associated with conservation objectives (Hall and Mainprize, 2004). Indicators are usually selected with regard to one specific driver of change. In the case of EBFM, indicators should respond in a predictable way to the fishing driver in its diverse forms (e.g., fishing effort, mortality, spatial allocation). If target reference points can be determined, the corresponding range of desirable fishing efforts can be estimated. When reference points cannot be determined due to the lack of sufficiently precise information on the ecosystem, the knowledge of reference directions can help to guide management measures, although there is no indication of whether success or failure to reach an objective is to be expected (Jennings and Dulvy, 2005). The difficulties faced when addressing reference points should not dissuade perseverance in that direction. The study led by (Shin et al. 2010a) showed that some consensus emerged in the estimation of reference points based on expert elicitation across various ecosystems. This consensus is particularly encouraging as it reinforces the ecological meaning of the indicators and suggests that very different ecosystems could be compared on the basis of simple indicators.

\section{Multispecies Maximum Sustainable Yield and fishing strategies}


Indicator reference points aim to reflect simultaneously a specific state of the ecosystem and whether some precise management objectives have been/can be met. By analogy to the mono-specific Maximum Sustainable Yield (MSY), which is a common target for fisheries agencies worldwide, we investigate reference points for ecosystem indicators for an ecosystem equivalent, namely Multispecies Maximum Sustainable Yield (MMSY) (Worm et al., 2009; Rindorf et al., 2016; Link, 2018).

So far, the regulation of fishing effort has been the primary lever of action to ensure the sustainability of a commercially exploited stock. Most often, when the state of a stock is evaluated, an estimate of the MSY is provided (and the associated fishing mortality $\left.F_{M S Y}\right)$ and translated into direct or indirect management decisions such as catch quotas until the next evaluation. Similar management procedures could be envisaged at the ecosystem scale by estimating the ecosystem exploitation rate allowing maximisation of the total catches, also referred to as Multispecies Yield (MY) (Worm et al., 2009: Jennings and Collingridge, 2015).

At the level of the ecosystem, the expected MMSY and the response of MY to fishing effort depend on how the latter is allocated between the different exploited stocks, hereafter referred to as the "fishing strategy". Recently, the fishing strategy has been shown to influence the performance of the fishing sector both in terms of production and conservation (Voss et al. 2014; Kolding et al., 2016). Because both the structure and productivity of an ecosystem largely depend on how it is exploited (Travers et al. 2006, 2010), it can be anticipated that, given the large range of potential harvesting strategies, a given management objective (e.g. MMSY) may be reached under different states of an ecosystem reflected by different values of ecosystem indicators. This potential variability of indicator reference points implies that they may not be considered as intrinsic values of an ecosystem, disregarding how it is exploited. However, rather than an obstacle to the practical use of ecosystem reference points to guide management decisions, their potential dependence on the fishing strategy could provide 
more flexibility in the appropriate management options and some mitigation opportunities. If an objective can be reached under different states of the ecosystem and fishing strategies, it opens the possibility to choose the best management option regarding other societal needs, such as conservation issues.

\section{The Southern Benguela case study}

Here, we were interested in the productive upwelling ecosystem of the Southern Benguela that has provided a pioneer case study on how to implement EBFM since the early 2000's (Shannon et al. 2004) and has been successfully implementing participatory approaches with various stakeholder groups (Jarre et al., 2018). The present work was designed more as an exploratory study on reference points rather than a concrete management plan for the Southern Benguela fisheries, and thus the choice of the objectives was not the core issue. The reference points considered hereafter refer to the values of a selection of ecosystem indicators when MMSY is reached. In order to quantify the variability of indicator reference points in a systematic way, we adopted a simulation approach to generate a large number of fishing scenarios. We used the individual-based model (IBM) OSMOSE (Shin and Cury, 2004) applied to the Southern Benguela ecosystem (Travers-Trolet et al., 2014a) to simulate 200 randomly-generated fishing strategies. The simulation plan aims at testing the existence of reference points which would be robust to a variety of fishing strategies. 


\section{Material and methods}

\subsection{OSMOSE model}

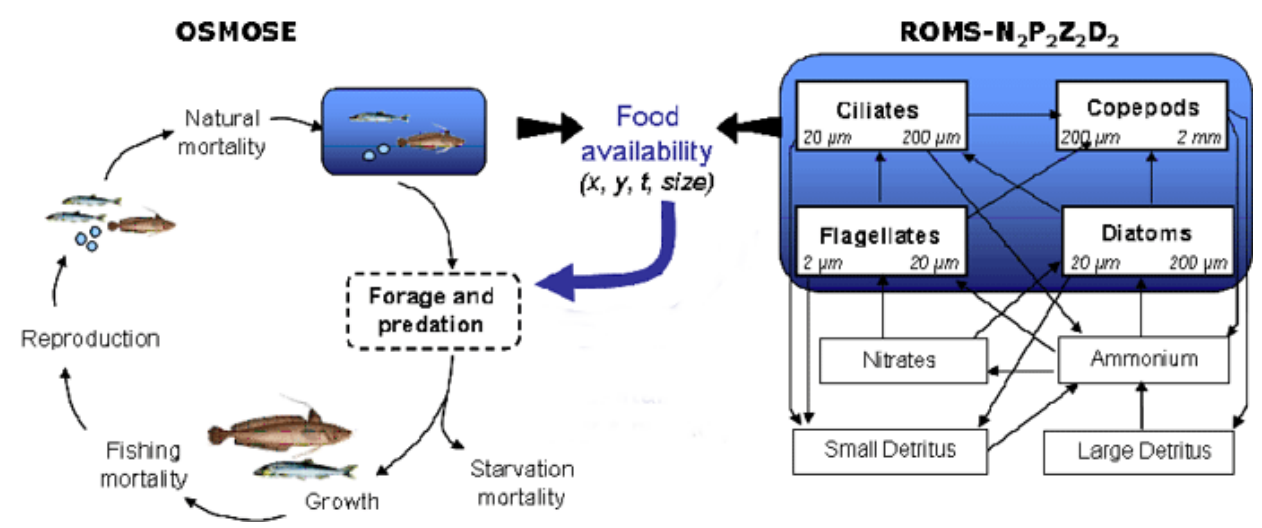

Figure 1: Schematic of the OSMOSE - ROMS- $N_{2} P_{2} Z_{2} D_{2}$ coupling. "One-way" coupling: the plankton represented by the Low Trophic Level (LTL) model ROMS- $N_{2} P_{2} Z_{2} D_{2}$ forces the High Trophic Level (HTL) model OSMOSE by providing prey fields to fishes.

Source: http://www.osmose-model.org/

The 2D individual-based model OSMOSE ("Object oriented Simulator of Marine Ecosystems") is a multispecies fish model relying on size-based opportunistic predation. Consequently, fish diets are solely the result of local prey availability and predator/prey size ratios (Shin and Cury, 2004). The modeled super-individuals represent fish schools sharing the same following characteristics: taxonomy, species-dependent life history traits, size, weight, age and geographical position on the horizontal grid. At each time step (every 15 days in our configuration), the characteristics of a superindividual evolve according to its life cycle (growth, predation, natural and starvation mortalities, reproduction, migration), to inter-individual interactions, and the fishing pressure exerted on its recruits. The fishing pressure for each species was implemented as a mortality rate for which the distribution within a year followed the observed seasonality of the different fleets in the Southern Benguela. At each time step, the number of fish removed by the fishery is: $N_{\text {dead } f i s h i n g}(t)=N(t)\left(1-e^{-F \times s(t)}\right), N(t)$ being the number of individuals at time $t$ and $s(t)$ the fraction of the annual fishing mortality exerted at time $t$. In order to resolve simultaneous mortality caused from different sources (fishing, predation, starvation, diverse additional), a stochastic algorithm was 
applied (www . osmose-model .org, Grüss et al. (2016)).

OSMOSE can be coupled "one way" or "two-ways" to a ROMS $N_{2} P_{2} Z_{2} D_{2}$ model simulating the dynamics of the lower trophic levels (Dinoflagellates, Diatoms, Ciliates and Copepods) (Koné et al. 2005: Travers et al., 2009: Travers-Trolet et al., 2014a). In the "one-way" coupling, the plankton represented by the LTL (low-trophic level) model ROMS- $N_{2} P_{2} Z_{2} D_{2}$ forces the HTL (high-trophic level) model OSMOSE by providing prey fields to fishes (Figure 1). The "two-way" coupling considers the feedback from the HTL model to the LTL model in the form of predation mortality on plankton groups by predation from higher trophic levels. For this particular study, the model was coupled "one-way" as running the two-ways coupled model for hundreds of scenarios would not have been tractable. Bi-weekly intra-annual variability in LTL forcing was incorporated. Ten key species or groups of species of the Southern Benguela ecosystem chosen for their importance in terms of biomass, catches or trophic role were represented in the high trophic level model OSMOSE (Shin et al., 2004): anchovy (Engraulis capensis), round herring, also commonly called "redeye" (Etrumeus whiteheadi), horse mackerel (Trachurus trachurus capensis), shallow water hake (Merluccius capensis), deep water hake (Merluccius paradoxus), snoek (Thyrsites atun), the remaining large pelagic species (e.g. kob, yellowtail, yellowfin tuna, albacore, carpenter) grouped in one functional group because they share similar life traits, the mesopelagic fish species Lampanyctodes hectoris and Maurolicus muelleri also grouped together, and euphausids (Euphausiacea). The spatial distribution of each species, accounting for possible ontogenic migrations, was documented by age-specific presence-absence maps found in the literature (maps from Travers-Trolet et al. (2014a) and updated with respect to the changes in distribution observed in the early 2000's documented in Watermeyer et al. (2016)).

Most species parameters of the model are common life history traits (reproduction, growth parameters, etc...) that were easily found in the literature (Table S1 in Online 
Supplementary Material, and Travers et al. (2009)). Nevertheless, some parameters remain largely unknown and were estimated using a heuristic optimization algorithm particularly suited to the calibration of stochastic models like OSMOSE (Duboz et al., 2010: Oliveros-Ramos and Shin, 2016). This was the case of the plankton accessibility factor (i.e. the fraction of the plankton biomass available to the higher trophic levels) and the larval mortality rate of the different species. Their estimation was done through the multi-phases minimization of an objective function (here, a log-likelihood objective function measuring the deviation between the outputs of the model and the historical biomass and catch data for the period 2000-2003) in the following order: 1) estimation of the plankton accessibility only, 2) estimation of the larval mortalities (one for each species or taxonomic group), and the plankton accessibility, and 3) estimation of the fishing mortality rates, along with the two previous sets of parameters. The configuration of the model running with those estimated parameters reached equilibrium after a spin-up time of circa 40 years. Because the time that the model takes to reach equilibrium can depend on the configuration, and the latter changed depending on the different scenarios of fishing strategies, the "spin-up" phase was extended to 60 years. All the ecosystem indicators addressed in this study were calculated from model state variables (biomass or yield outputs structured, or not, by age or size classes or trophic levels), averaged over the period 60-80 years. Moreover, because OSMOSE is a stochastic model, 30 replicates of each configuration were run, over which the output state variables were averaged.

\subsection{Ecosystem Indicators}

Since landings data are known to be biased due to illegal, unreported and unregulated (IUU) fishing, which may represent up to one third of the global reported catches (Agnew et al. 2009), complementary indicator reference points other than those based solely on reported catches have the potential to improve the assessment of fishing impacts and to operationalize EBFM.The existence of reference points was tested for the set of ecological indicators selected by the working group IndiSeas (Coll et al., 2016. 
Table 1: Summary of the various ecosystem indicators tested in the present study. Only surveyed species were considered to calculate survey-based indicators and only harvested species were considered for the calculation of catch-based indicators. Whether a species is surveyed, harvested or considered as a predator is documented in Table S1](Online

Supplementary Material). $N$ refers to number of individuals, $B$ to biomass in the ecosystem, $Y$ to yield, $M Y$ to multispecies yield, IVI to the intrinsic vulnerability index, max age to species life span, max size to species maximal size, and $T L$ to trophic level. Subset $s p$ stands for species, and size lim and $T L_{l i m}$ are the size and TL thresholds used in the calculation of some indicators.

\begin{tabular}{|c|c|c|c|c|}
\hline Indicator & Abbreviation & Calculation & Type & Unit \\
\hline Total Biomass & $T B$ & $\sum_{s p} B_{s p}$ & survey-based & MT \\
\hline $\begin{array}{l}\text { Inverse of fishing } \\
\text { pressure }\end{array}$ & $B \_Y$ & $T B / M Y$ & survey-based & $\varnothing$ \\
\hline $\begin{array}{l}\text { Intrinsic } \\
\text { Vulnerability } \\
\text { Index of the } \\
\text { landings }\end{array}$ & IVI & $\frac{\sum_{s p} I V I_{s p} \times Y_{s p}}{M Y}$ & catch-based & $\varnothing$ \\
\hline $\begin{array}{l}\text { Large Fish } \\
\text { Indicator }\end{array}$ & $L F I\left(\right.$ size $\left._{\text {lim }}\right)$ & $\frac{\sum_{\text {size }>\text { size } e_{\text {lim }}} B_{\text {size }}}{T B}$ & survey-based & $\varnothing$ \\
\hline Mean Size & $L G$ & $\frac{\sum_{\text {size }} \text { size }}{N}$ & survey-based & $\mathrm{cm}$ \\
\hline Mean Life Span & LS & $\frac{\sum_{s p} \operatorname{maxage}_{s p} \times B_{s p}}{T B}$ & survey-based & year \\
\hline $\begin{array}{l}\text { Mean Maximal } \\
\text { Size }\end{array}$ & $M M L$ & $\frac{\sum_{s p} m a x s i z e_{s p} \times B_{s p}}{T B}$ & survey-based & $\mathrm{cm}$ \\
\hline $\begin{array}{l}\text { Marine Trophic } \\
\text { Index }\end{array}$ & $\operatorname{MTI}\left(T L_{l i m}\right)$ & $\frac{\sum_{T L>T L_{l i m}} T L \times Y_{T L}}{M Y}$ & catch-based & $\varnothing$ \\
\hline $\begin{array}{l}\text { Proportion of } \\
\text { predatory fish }\end{array}$ & $P F$ & $\frac{B_{\text {predators }}}{T B}$ & survey-based & $\varnothing$ \\
\hline $\begin{array}{l}\text { Size spectrum } \\
\text { slope }\end{array}$ & SSS & $\begin{array}{l}\text { opposite slope of } \\
\log (\text { abundance })= \\
\mathrm{f}(\log (\text { size }))\end{array}$ & survey-based & $\varnothing$ \\
\hline $\begin{array}{l}\text { Trophic level of } \\
\text { landings }\end{array}$ & $T L L$ & $\frac{\sum_{s p} T L_{s p} \times Y_{s p}}{M Y}$ & catch-based & $\varnothing$ \\
\hline $\begin{array}{l}\text { Trophic level of } \\
\text { surveyed } \\
\text { community }\end{array}$ & TLS & $\frac{\sum_{s p} T L_{s p} \times B_{s p}}{T B}$ & survey-based & $\varnothing$ \\
\hline
\end{tabular}

Shin et al. 2010b). Three indicators commonly used for the European Marine Strategy

Framework Directive were added to this list: the large fish indicator LFI (Greenstreet et al., 2011), the mean maximum length $M M L$ (Jennings et al., 1999), and the slope of 
the size spectrum SSS (Shin et al., 2005). A summary of their calculation is presented in Table 1 and additional information in Table S2 (Online Supplementary Material).

Further refinements of indicators like the large fish indicator $L F I$, the marine trophic index MTI or size spectrum slope SSS are possible by considering different size or trophic level thresholds or ranges. Because an indicator calculated at different thresholds can give complementary insights on the dynamics of a community (Shannon et al. 2014), we deemed it important to assess whether the choice of the threshold influenced the sensitivity of the associated reference points to the harvesting strategy. The large fish indicator was calculated by considering fishes larger than $20 \mathrm{~cm}$ (LFI20) and $30 \mathrm{~cm}$ (LFI30). The marine trophic index was calculated at 4 thresholds, i.e. considering fish of which the trophic level (TL) is higher than 3.25 (the reference threshold), 3.5, 3.75, and 4.0 (threshold suggested by Shannon et al. (2014) and Coll et al. (2016) for upwelling ecosystems like the Southern Benguela). Finally, the size spectrum slope was calculated by considering fish between 10 and $60 \mathrm{~cm}$ (SSS60) and 10 and 100cm (SSS100) (Shin et al., 2005).

\subsection{Testing the sensitivity of ecosystem-based reference points to} the fishing strategy

\subsubsection{Reference points at MMSY}

The aim of the first part of the study was to explore the variability of reference points for ecosystem indicators across a wide range of fishing strategies. The hypothesis tested is that a variety of fishing strategies leads to variable MMSYs that potentially underlie contrasted statuses of fish stocks as reflected by different values of indicator reference points.

In our simulations, a fishing strategy $S$ reflected a given distribution of the fishing effort among the different exploited species (i.e. all species except euphausids and 
mesopelagic fish). Formally, it was defined as a vector of fishing mortality rates, one for each species. In order to assess the sensitivity of the indicators' reference levels to the fishing strategy, 200 randomly generated fishing strategies were simulated. For each fishing strategy, the fishing mortality rate $S[s p]$ of the species $s p$ was drawn between $0.05 \mathrm{yr}^{-1}$ and $F_{\text {collapse }}[s p]$, the latter being the fishing mortality rate at which the species $s p$ collapsed (i.e. reached $10 \%$ of its virgin biomass) while all other species remained fished at their estimated levels for the period 2000-2003 (Table S1). The response of each species to the fishing pressure was determined with the function $F \_m s y$ from the R package osmose $2 R$ (www . osmose-model .org). The lower bound of $0.05 y^{-1}$ referred to the minimal fishing rate among the exploited species obtained after calibration for the period 2000-2003, and was imposed in order to reach the MMSY for reasonable values of the multiplier $\lambda$ of fishing mortality rates (defined hereunder).

For each strategy, we increased the fishing pressure on all species by multiplying the vector $S$ by a factor $\lambda$. The vector of fishing mortality rates corresponding to a fishing multiplier $\lambda$ was thus defined as: $F=\lambda \times S$. Fishing pressure kept increasing until MMSY was reached for each strategy. Because the fishing multiplier $\lambda$ at which the MMSY was reached strongly varied between strategies, it was not relevant to fix a priori the values taken by $\lambda$. They were thus determined for each strategy independently according to the following algorithm (Figure S1- Online Supplementary Material):

1. A first estimate of $\lambda_{M M S Y}$ (the value of $\lambda$ at which the MMSY was reached) was made through a coarse screening of the fishing multipliers at a step $\Delta \lambda_{1}=10$ between $\lambda=0$ and $\lambda=500$.

2. This first estimate of $\lambda_{M M S Y}$ set the upper bound of a second screening of $\lambda$ with $20 \lambda$ values equally distributed between $\lambda=0$ and $\lambda=\lambda_{M M S Y}+2 \times \Delta \lambda_{1}$. So the finer second step applied is $\Delta \lambda_{2}=\frac{\lambda_{M M S Y}+2 \times \Delta \lambda_{1}}{20}$.

3. Finally, $\lambda$ steps were further refined at the beginning of the $M Y$ curve (between 
$\lambda=0$ and $\Delta \lambda_{2}$ ) and around $\lambda_{M M S Y}$ (between $\lambda_{M M S Y}-\Delta \lambda_{2}$ and $\lambda_{M M S Y}+\Delta \lambda_{2}$

) with a step $\Delta \lambda_{3}=\frac{\Delta \lambda_{2}}{10}$. These refinements were made to improve the curve fittings described hereunder.

Simulated values of multispecies yield $(M Y)$ as well as other ecosystem indicators were then generalized so that: (1) MMSY and the reference points of ecosystem indicators at MMSY could be better approached, and (2) the evolution of the indicators with the fishing multiplier could be reconstructed at regular intervals. As we were not interested in the actual parameters from a model fitting the data, we chose to generalize the data based on local polynomial regressions (loess function from the R package stats) as it allowed to fit the data more closely especially in the presence of plateau or abrupt changes in slope. In $10 \%$ of the simulated scenarios, total catches would reach a plateau at MMSY and not display the typical bell-shaped curve. Because increasing fishing effort once total catches have reached a plateau would cause economic losses for the fisheries, we deemed it relevant to estimate MMSY as the beginning of the plateau. The beginning of the plateau was generally observed at 98\% of MMSY. Estimating MMSY as $98 \%$ of the real MY maximum was therefore a satisfying option to similarly treat both bell-shaped and plateau curves. The curve fitting of $M Y$ allowed estimation of $\lambda_{M M S Y}$ as the abscissa at which $98 \%$ of the $M Y$ maximum was reached. Finally, the reference points of the various indicators were determined as the values of the fitted indicators at $\lambda=\lambda_{M M S Y}$.

\subsubsection{Testing the robustness of reference points across fishing strategies}

For each indicator, the set of reference points at MMSY for the 200 simulated fishing strategies defined what we called its reference distribution (200 values per indicator), and the interdecile range $[Q 10 ; Q 90]$ of this distribution defined its reference interval. The total distribution of an indicator referred to the whole set of values the latter could take, independently of the strategy or fishing intensity $\lambda$. It was reconstructed by extracting 100 values of the indicator (equally distributed between $\lambda=0$ and $\lambda_{M M S Y}$ (20 000 values per indicator)) for each strategy from the fitted indicator's curves for that 
strategy .

Whether an indicator displayed typical values at MMSY that could be used as alternative target reference points, or proxies, for MMSY was investigated by calculating the proportion of its total distribution contained in its reference interval. An indicator was considered as useful to detect when MMSY was reached regardless of the fishing strategy when less than $10 \%$ of its total distribution fell within its reference interval.

For visualization purposes, and comparison between indicators, standardized indicators were calculated as: $\frac{\text { value - mean of the total distribution }}{\text { standard deviation of the total distribution }}$.

\subsubsection{Testing the robustness of reference points within fishing strategies}

If our hypothesis is confirmed, ecosystem indicators may be too sensitive to the fishing strategy for their reference points at MMSY to be set regardless of fishing strategy. In this case, strategy-specific reference values are likely to provide more robust proxies for MMSY. Still, because of the stochastic nature of the model (cf 2.1), a single set of inputs (of particular interest in this work: the fishing strategy $S$ and fishing intensity $\lambda$ ) will result in different outputs (the ecosystem indicators). As a consequence, strategyspecific reference levels should be expressed in terms of confidence intervals rather than single values. For each strategy, robust indicators at MMSY were identified as the ones for which less than $10 \%$ of the total distribution of the indicator in the strategy was contained in the $95 \%$ Student based confidence interval of the mean of the mean reference point across the 30 replicates. This allowed us to identify the indicators that were the most likely to provide robust strategy-specific proxies for MMSY.

\subsection{Focus on realistic fishing strategies in the Southern Benguela}

In addition to these exploratory analyses, we gave special attention to more realistic fishing strategies in the Southern Benguela. These strategies explicitly accounted for technical interactions among species simultaneously caught by a fishing fleet. Indeed, the various fishing fleets in the Southern Benguela are not species-specific (i.e. they 
do not target a single species but catch many species in various proportions), and it is thus not realistic to apply uncorrelated fishing pressures on the various species. The same methodology as described in 2.3.3 was used to determine which indicators could be used as robust proxies for MMSY.

\subsubsection{Reaching MMSY by increasing the fishing effort on all species}

The first scenario simulated an increase of the fishing effort on all species proportionally to their exploitation levels for the period 2000-2003. This was done by multiplying the vector of fishing mortality rates $F_{2000-2003}$ estimated by the calibration algorithm to fit the mean annual catches for the period 2000-2003 (Table S1) by a fishing multiplier $\lambda$ until MMSY was reached. This scenario would correspond to simultaneously developing all South African sectors from their 2000-2003 levels.

\subsubsection{Reaching MMSY by developing only some fishing sectors}

Rather than increasing the fishing effort of all fleets, one could also imagine reaching MMSY by developing only some fishing sectors. This could be done to preserve the most vulnerable stocks for instance. We successively explored the development of two fishing sectors, namely the purse seine fishery catching mostly the small pelagic species such as sardine, anchovy and redeye, and the hake trawl fishery targeting both hake species but also catching large pelagic species and horse mackerel. We chose to focus on those 2 sectors as they account for most of the reported catches (the purse seine and hake trawl sectors respectively accounted for $70 \%$ and $25 \%$ of the total landings between 2003 and 2014). For each modelled species, the proportion of its annual catches attributed to each sector was calculated from official annual catch data by sector (data records of the Department of Agriculture, Forestry and Fisheries, South Africa). Annual landings of each species of each sector were averaged between 2003 and 2014, which is the period for which data was available. The contribution of each sector to the catches of each species is reported in Figure 2. For each sector separately, we multiplied the fishing effort by a factor $\lambda$. The resulting fishing mortality rate for 
the species $s p$ for which a proportion $p[s p]$ is caught by the developing fishing fleet was calculated as : $F[s p]=F_{2000-2003}[s p] \times((1-p[s p])+\lambda \times p[s p])$. In this way, only the proportion of the fishing mortality rate attributed to the selected developing fishing sector increased by a factor $\lambda$.

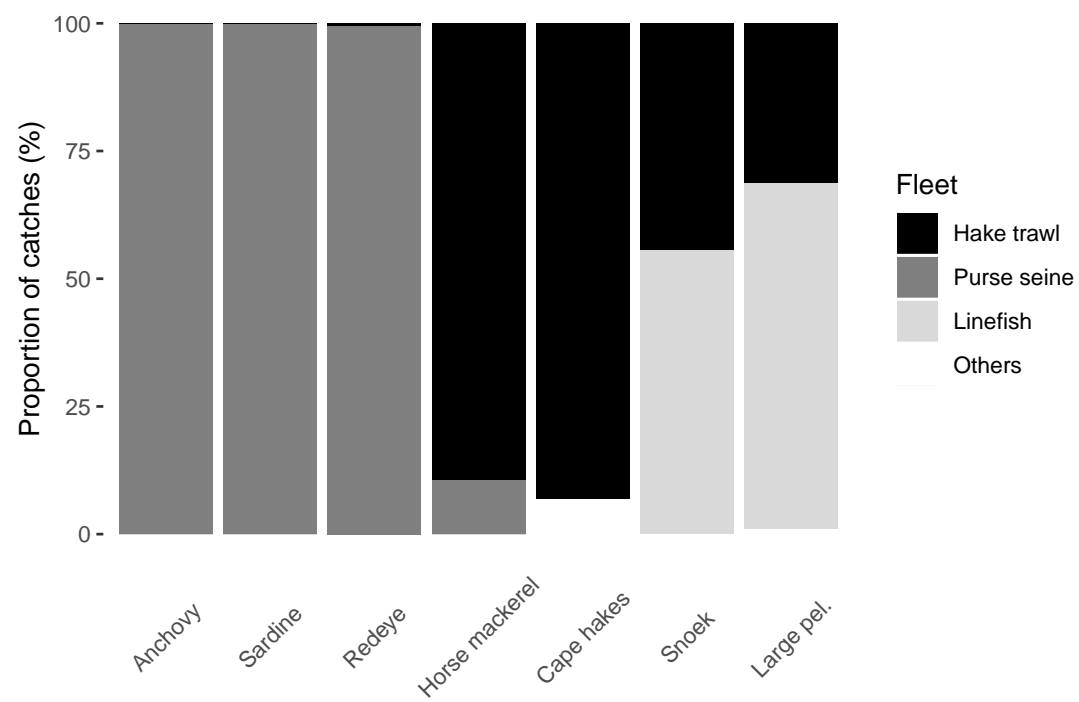

Figure 2: Mean contribution of each fishing sector to the landings of the modeled commercial species between 2003 and 2014

\section{Results}

\subsection{High sensitivity of the reference points to the fishing strategy}

By looking at the tails of indicator density functions (Figure 3), it appeared that the reference distributions of all indicators were narrower than their total distributions. However, the proportion of the total distribution that fell within the reference interval was much higher than $10 \%$ for all indicators (Figure 3). This means that, without specification on how MMSY is expected to be reached (i.e. the fishing strategy), the ranges of values taken by the tested ecosystem indicators at MMSY were too wide to constitute robust signals that MMSY had been reached. In other words, there is no "one size fits all" value for those indicators that could help track MMSY: they are dependent on the fishing strategy. 


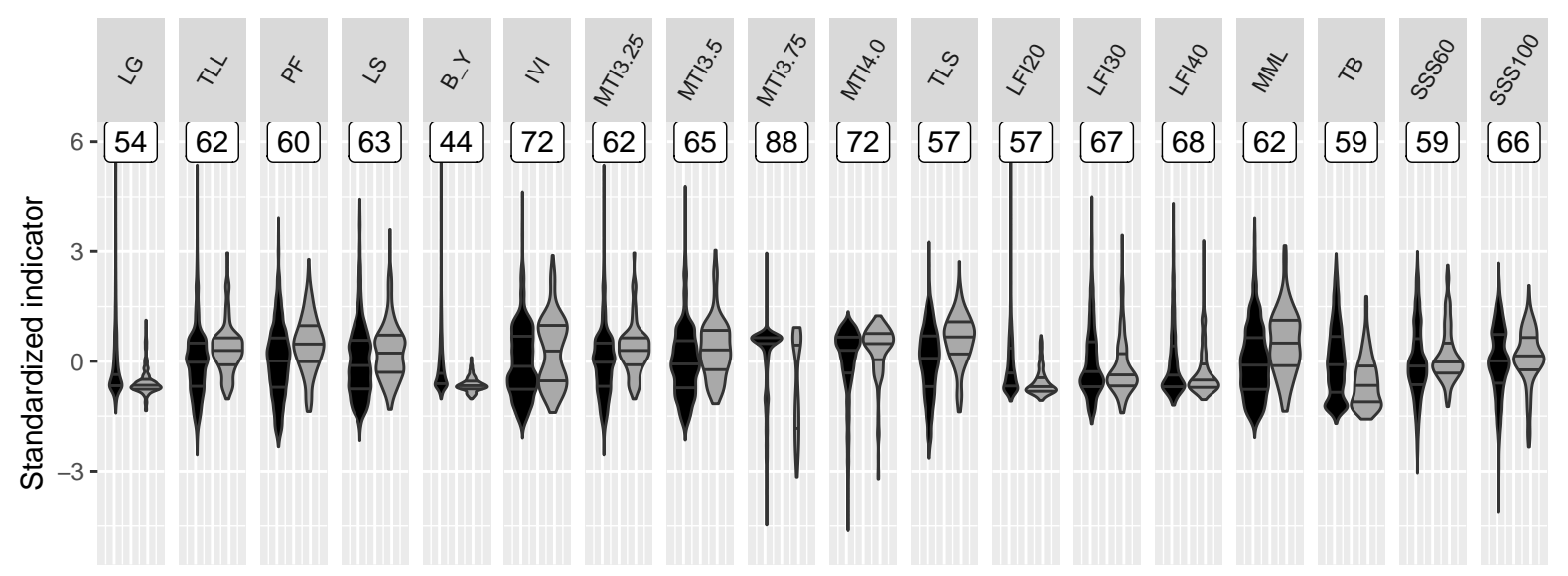

Figure 3: Distributions of the standardized indicators and their reference points (all randomly generated fishing strategies included). Refer to Table 1 for the indicators' definition. In black: the total distribution of all indicator values across all strategies $(n=20000)$, in gray: the reference distribution, i.e. the distribution of the reference points at MMSY across all strategies $(n=200)$. Numbers indicate the percentage of the total distribution of the indicator that fell within the interdecile range of its reference distribution.

\subsection{Strategy-specific reference points at MMSY}

As shown on Figure 4 A, all indicators were not equally useful in detecting when MMSY had been reached. The indicators $B_{-} Y, L S, T B, M M L$ and LFI20 appeared as the most likely to provide robust proxies for MMSY, as their confidence interval at MMSY had less than 10\% overlap with the total distribution of the indicator in more than $60 \%$ of the simulated strategies. It is worth noting that the thresholds used for calculating indicators such as the marine trophic index MTI, the large fish indicator LFI or the size spectrum slope SSS influenced their robustness. This is especially striking for the large fish indicator which could be used as a proxy in $60 \%$ of the strategies when calculated at a threshold of $20 \mathrm{~cm}$, but was only useful in $25 \%$ (respectively $16 \%$ ) of the strategies when calculated at a threshold of $40 \mathrm{~cm}$ (respectively $30 \mathrm{~cm}$ ). The size spectrum slope was in general more useful when calculated at a threshold of $60 \mathrm{~cm}$ ( $40 \%$ of the strategies) than when calculated at a threshold of $100 \mathrm{~cm}(15 \%$ of the strate-

gies). The mean trophic index appeared slightly more likely to provide a robust proxy for MMSY when calculated at thresholds of 3.5 or $3.75 \mathrm{~cm}$ (respectively 38 and 34\% of the strategies) than when using the commonly used threshold of 3.25 (31\% of the strategies). 

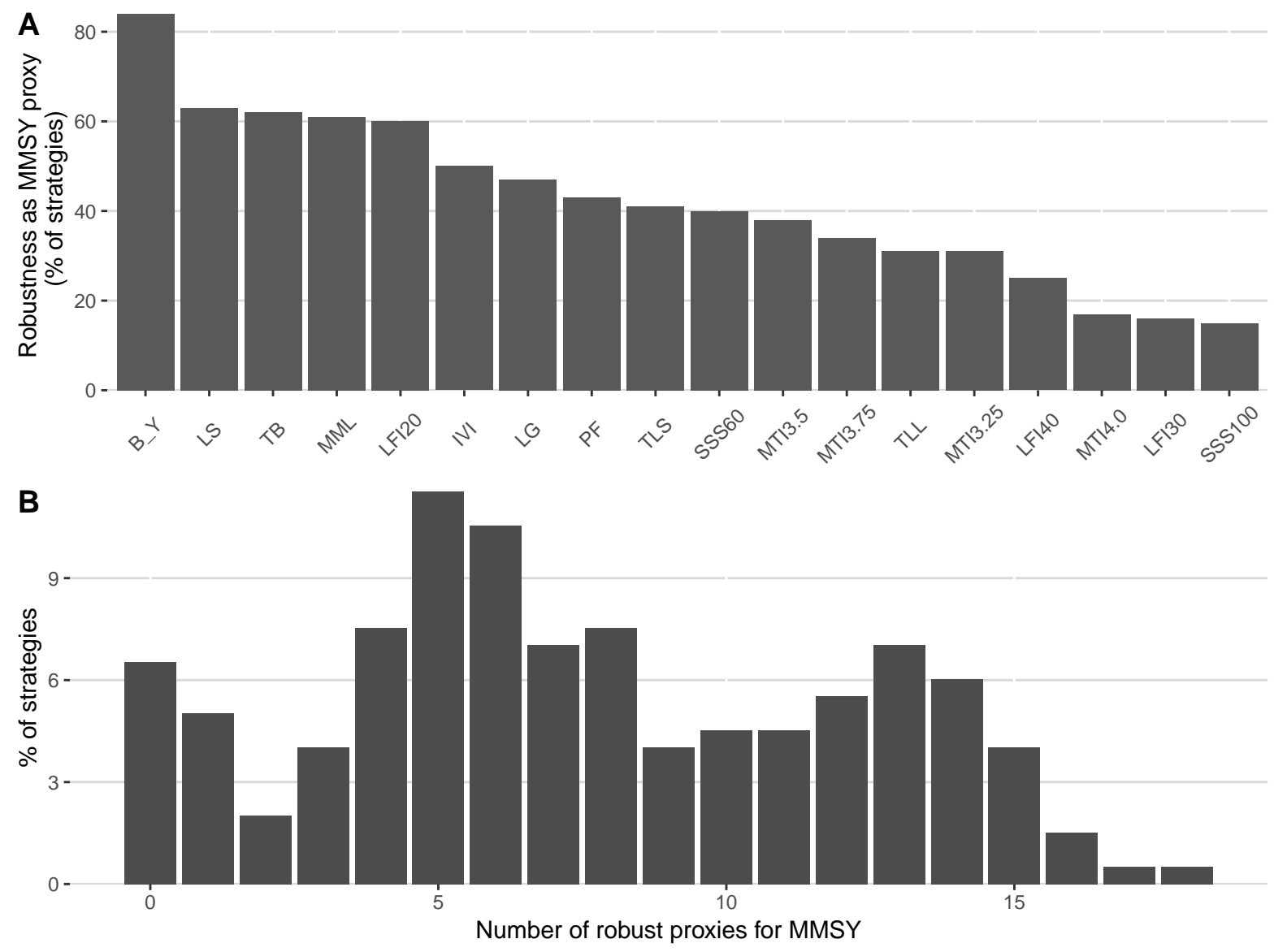

Figure 4: A- Percentage of strategies in which the indicator was a useful proxy for MMSY (i.e. less than $10 \%$ of the total distribution of the indicator fell within the $95 \%$ confidence interval of its reference point at MMSY)

B- Histogram of robust proxies for MMSY across the 200 simuated strategies (in \%). For example, $7 \%$ of strategies did not have a robust proxy for MMSY, in 5\% of them, one indicator could be used as a robust proxy, in $2 \%$ of them 2 indicators could be used, etc...

As shown on Figure $4-B$, only $7 \%$ of strategies did not have a robust proxy indicator for MMSY which means that at least one indicator among the proposed list provided a robust proxy for MMSY in more than $93 \%$ of the strategies. MMSY could be detected by more than one indicator in $88 \%$ of the strategies (bins 0 and 1 account for $12 \%$ of the strategies). In those cases, monitoring the ecosystem with a suite of indicators rather than a single one could increase the reliability of the assessment. 


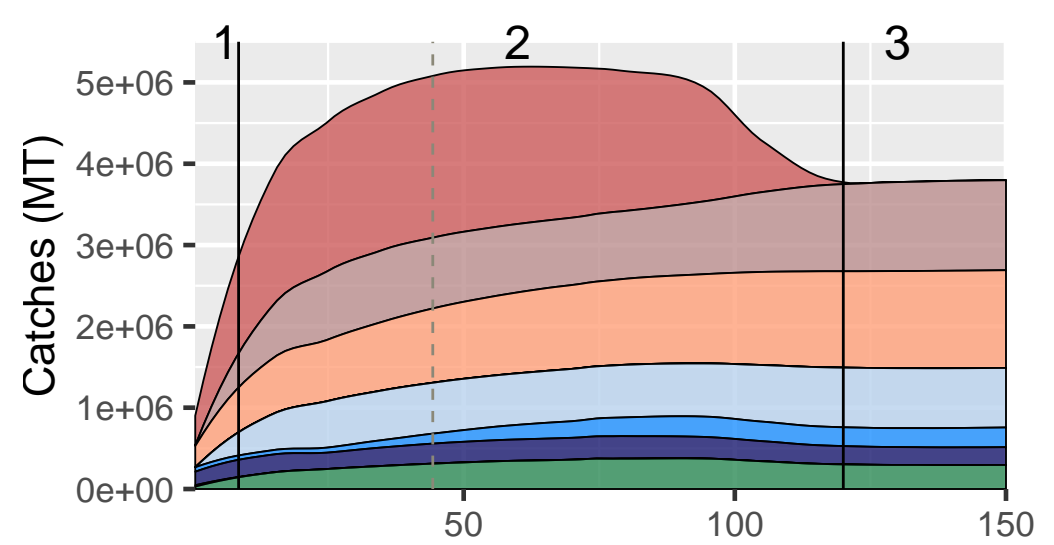

\section{species}

\begin{tabular}{l|l}
\hline & anchovy \\
& redeye \\
& sardine
\end{tabular}

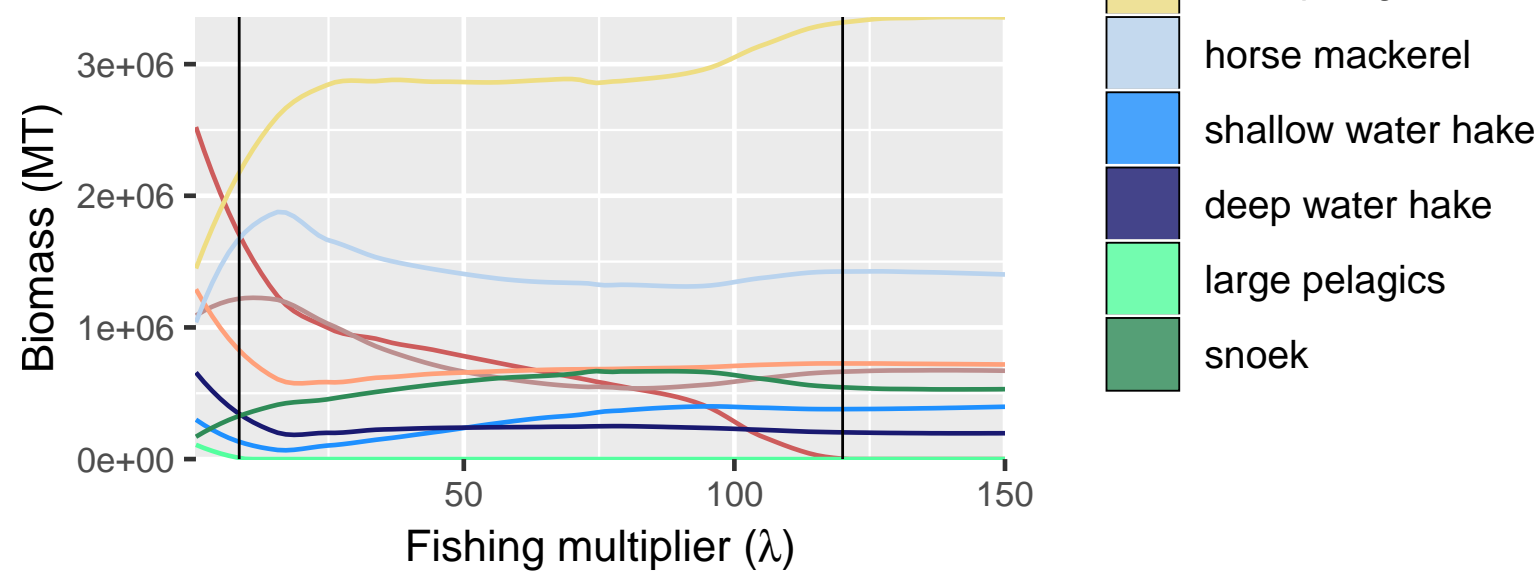

Figure 5: Cumulated yield and biomass of the modelled species when fishing pressure increases proportionally to the 2000-2003 configuration. The response of the community to the increase of fishing effort on all species could be divided in 3 parts delimited by vertical black lines. The vertical dashed line indicates $98 \%$ of MMSY

\subsection{Focus on more realistic fishing strategies}

When fishing pressure increased on all species proportionally to the 2000-2003 levels, the response of the ecosystem could be divided into 3 main phases as illustrated by Figure 5

- Phase 1: The strong decrease in anchovy biomass released competition pressure for large zooplankton (euphausids), which largely benefited horse mackerel and redeye, the biomass of which increased despite increasing fishing pressure (starting from current fishing mortalities almost three times lower than that of anchovy, Table S1). However, it did not benefit sardine, which feeds on smaller plankton (mainly copepods and diatoms) and which decreased in biomass in 


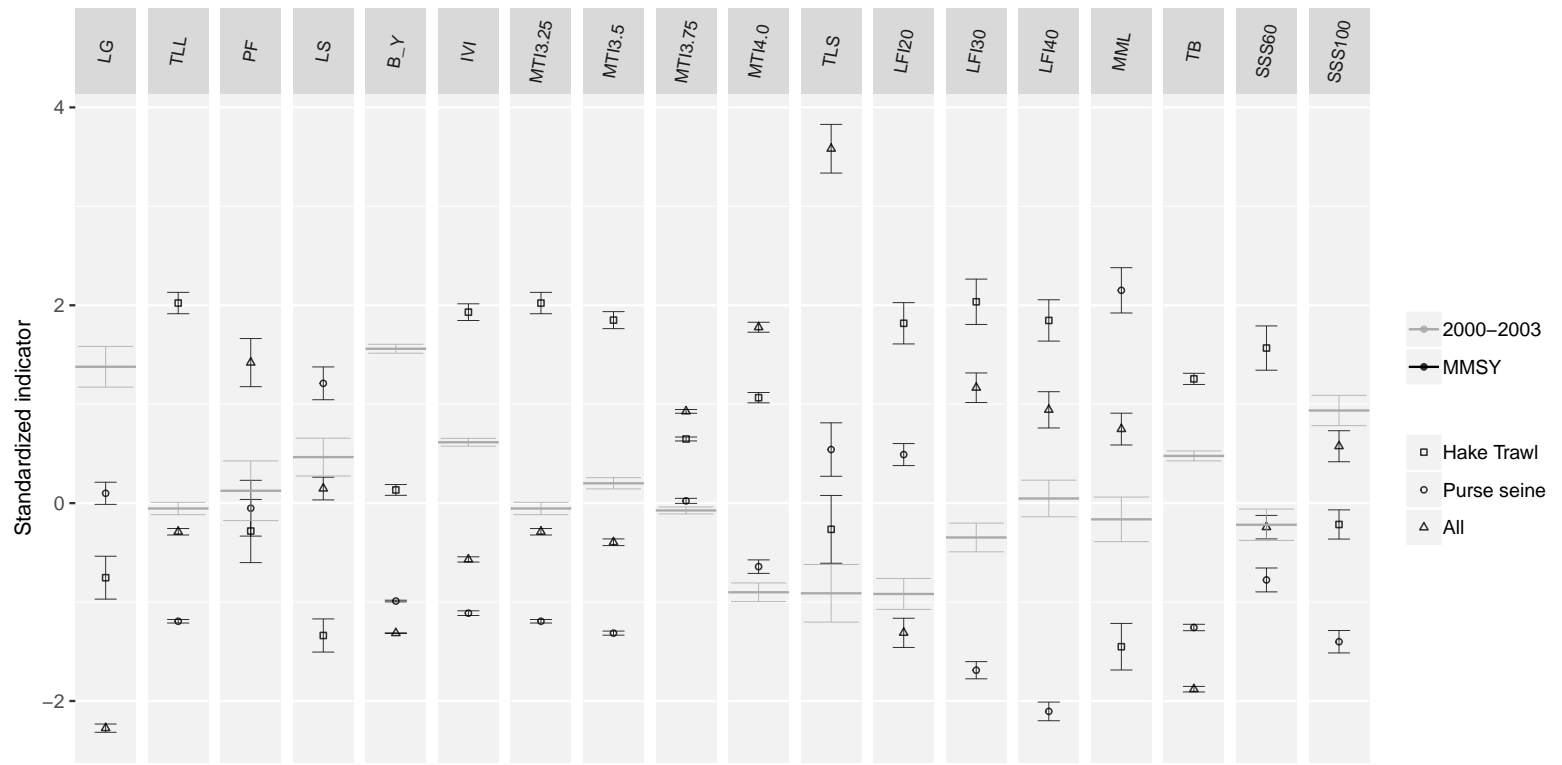

Figure 6: Standardized reference points at MMSY for realistic fishing scenarios in the Southern Benguela and their $95 \%$ confidence interval. To be compared with the indicator's value when fishing effort is maintained at 2000-2003 levels (in grey). 
95\% confidence interval are presented in Figure 6. As expected, the values of the reference points depended on the fishing strategy under which MMSY was reached. Moreover, for some indicators, we could not even provide a reference direction from the 2000-2003 situation (i.e. $\lambda=1$ ) towards MMSY that would be common to all scenarios.

For instance, the reference point at MMSY for the mean maximum length $(M M L)$ was lower than its 2000-2003 value when only the hake trawl fishery developed, whereas it was greater than the 2000-2003 value for the other scenarios. This highlights the fact that, even though those indicators were originally designed to decrease when fishing pressure increases, they do not always behave that way. The only indicators that showed a common reference direction in all three strategies were $L G, B \_Y, M T I 3.75$, MTI4.0, TLS, and SSS100.

Again, the indicators that provided robust proxies for MMSY depended on the strategy. The indicators that could be useful to detect MMSY in each scenario are highlighted in Table 2. The only indicator that provided robust reference levels in all three strategies was the mean life span indicator $L S$.

\section{Discussion}

Just like the single species MSY is attached to a fishing strategy (for example, depending on size of recruitment, seasonality, spatial distribution of effort, etc...), results presented here confirmed our assumption that MMSY is particular to a multispecies fishing strategy (i.e. how fishing effort is distributed across species). As a consequence, we showed that robust proxies for MMSY based on ecosystem indicators could not be set without considering the context under which MMSY is reached. However, in more than $93 \%$ of the simulated strategies, strategy-specific reference levels for ecosystem indicators could be used to detect when MMSY had been reached. In more than $88 \%$ of the cases, there were at least two indicators that could be used as proxies for MMSY. In these cases, a monitoring process based on several indicators could increase the re- 
Table 2: Indicators that provide robust proxies for MMSY under realistic fishing scenarios (i.e. the ones for which less than $10 \%$ of the values taken in the scenario is contained in the $95 \%$ confidence interval of the reference point at MMSY) are highlighted in gray

\begin{tabular}{|c|c|c|c|}
\hline & All & $\begin{array}{l}\text { Purse } \\
\text { Seine }\end{array}$ & $\begin{array}{l}\text { Hake } \\
\text { trawl }\end{array}$ \\
\hline \multicolumn{4}{|l|}{ B_Y } \\
\hline \multicolumn{4}{|l|}{ IVI } \\
\hline \multicolumn{4}{|l|}{ LFI20 } \\
\hline \multicolumn{4}{|l|}{ LFI30 } \\
\hline \multicolumn{4}{|l|}{ LFI40 } \\
\hline \multicolumn{4}{|l|}{ LG } \\
\hline \multicolumn{4}{|l|}{ LS } \\
\hline \multicolumn{4}{|l|}{ MML } \\
\hline \multicolumn{4}{|l|}{ MTI3.25 } \\
\hline \multicolumn{4}{|l|}{ MTI3.5 } \\
\hline \multicolumn{4}{|l|}{ MTI3.75 } \\
\hline \multicolumn{4}{|l|}{ MTI4.0 } \\
\hline \multicolumn{4}{|l|}{$\mathrm{PF}$} \\
\hline \multicolumn{4}{|l|}{ SSS100 } \\
\hline \multicolumn{4}{|l|}{ SSS60 } \\
\hline \multicolumn{4}{|l|}{ TB } \\
\hline \multicolumn{4}{|l|}{ TLL } \\
\hline TLS & & & \\
\hline
\end{tabular}

liability of the assessment of the ecosystem relative to MMSY.

Two approaches can be used to estimate reference points based on the maximization of some utility function: constrained or unconstrained optimization. Whereas the unconstrained approach only seeks to maximize a utility function, constrained optimization methods look at maximizing a utility function while respecting other constraints. These other constraints can express other objectives not accounted for in the utility function (e.g. maintaining all stocks above a limit biomass, maintaining biodiversity, ensuring minimum profits for the fishery...) or reflect inflexibilities in the system (e.g. as some species are sometimes caught jointly, one might have to constraint ratios in fishing mortalities). Maximizing multispecies yield without con- 
straints would have given us the optimal combination of fishing mortalities, whereas specifying how fishing mortalities are linked to each other gave us an estimate of MMSY for a given multispecies fishing strategy. Some authors have already stressed the inadequacy of unconstrained optimizing solutions in complex systems where different objectives often have to be traded off against each other (Voss et al., 2014; Moffitt et al. 2016: Tromeur and Doyen, 2018). As put forward by Fogarty (2014), ecosystembased management might be a matter of agreeing on a satisfactory solution rather than looking for the optimal one, and this requires to assess the performance of various management options regarding a specified set of objectives.

We only studied reference points associated with MMSY, but could reasonably expect similar conclusions under other management objectives (e.g. conservation or economic objectives). The situation may even be clearer cut when one attempts to identify thresholds at the point of ecosystem collapse, such as is being test-run under the IUCN red listing process for ecosystems (Keith et al., 2013; Bland et al., 2018), and limit reference points for different ecological indicators that signal the thresholds beyond which an ecosystem is considered to be in a degraded state, such as was done in the IndiSeas project (Shin et al. 2010a).

Although one motivation of this work was that unreliable estimations of catches might undermine the assessment of the ecosystem relative to the objective of maximizing sustainable catches, we did not exclude catch-based indicators from our study altogether. Our catch-based indicators did not rely on absolute values of catches, but rather reflected the species contribution to total catches or catches relative to biomass. Whether relative values of catches are less biased than absolute values should be explored if reference points on catch-based indicators are to be used as proxies for MMSY.

Reference points at MMSY or at fishing levels under specific management objec- 
tives could supplement the work that has already been carried out on indicator trends (Blanchard et al., 2010; Coll et al., 2010, 2016). We would suggest that both approaches (reference points and indicators trends) be given due attention as the responses of indicators is not as straightforward as initially thought. In particular, ecosystem indicators do not always decrease with fishing pressure, as was found for some indicators under specific fishing strategies. An increase in trophic -based indicators with fishing pressure is evident from research surveys (Shannon et al., 2014, Coll et al., 2016) and has been found for both trophic- and size-based indicators under specific fishing strategies in some modelling studies(Travers et al., 2006; Branch et al., 2010).

Apart from not decreasing with fishing pressure, some indicators might also show a non-monotonic response to fishing pressure. From our simulations, we noticed that the changes in slope in the response curves of indicators were often dependent on community shifts, some species taking advantage over others from a certain exploitation level. It is because such shifts in indicators' slope might occur on the trajectory towards MMSY that we strongly recommend considering indicator trends in addition to targeted values.

We also noticed that under many fishing strategies, total catches would not display the typical bell-shaped curve often presented (Worm et al., 2009) but would instead reach a plateau or only decrease very slowly once MMSY has been reached (Figure S2 - Online Supplementary Material). The resilience of the ecosystem to high fishing pressure in these particular scenarios could be explained by several factors: (i) only fishing effort varied in our simulations, not size selectivity of a fishery, for example, nor the fishing spatial distribution, which in reality may allow some age classes to be inaccessible to the fishery; (ii) modelled fishing strategies did not include mesopelagic fish as a caught species, hence preserving a potentially huge prey biomass fueling the production of exploited species; (iii) the high intrinsic model growth rates of some species such as anchovy, sardine and redeye; (iv) the modelled fishing seasonality or 
age of recruitment to the fishery allowed part of the populations to reproduce before being fished. All these factors in addition to the multispecies interactions and the high primary production of the system could favor the persistence of modelled ecosystem biomass under certain fishing scenarios, even at high fishing levels. This echos compensatory responses of harvested stocks that may arise when interactions with the rest of the ecosystem are accounted for (Walters et al., 2005). Because this was not the core issue of our paper we here provide plausible explanations until further work dedicated at properly identifying the mechanisms allowing such resilience is undertaken.

Importantly, depending on the fishing strategy, different indicators should be used to evaluate how far the ecosystem is from MMSY (and hence from ecosystem overexploitation). Furthermore, indicators such as LFI, MTI or SSS responded differently when calculated at different thresholds. This is an interesting feature to take into account as it can improve the performance of these indicators in detecting when targets or limits are reached. Therefore, we advise that preliminary model analyses specific to the ecosystem and fishing strategy be carried out to capture the variable robustness of indicator reference points.

Results from this study show that we can identify robust reference levels at MMSY for specific indicators. Whether our conclusions hold when environmental variability comes into play remains to be seen. Indeed, as the state of ecosystems is also strongly driven by environmental factors (Cury and Shannon, 2004: Travers-Trolet et al., 2014b; Fu et al., 2015; Large et al., 2015; Fu et al., 2018), higher uncertainty around indicator reference points is likely to arise if inter-annual climate variability or trend is taken into account. Model simulations run to test performance of ecological indicators found that in general, IndiSeas-proposed indicators were fairly good at responding to fishing pressure even under environmental perturbations, although interpretation of indicator trends required careful consideration of ecosystem characteristics and fishing strategy (Shin et al., 2018). Nevertheless, it seems feasible to produce ecosystem-specific, 
fishing-strategy-specific sub-sets of indicators with carefully determined reference levels to guide fisheries management decisions.

\section{Conclusion}

When the estimation of catches is undermined by illegal, unreported and unregulated fishing, using other ecological indicators to monitor total catch (and ecosystem effects of that catch) may be a useful and interesting alternative to assess how far we are from maximizing sustainable catches. By exploring a wide range of fishing strategies, we showed that we are very likely to find at least a robust proxy for MMSY using a set of ecosystem indicators. We also highlighted that the set of ecosystem indicators potentially usable as warning signs that MMSY has been reached depends on the fishing strategy, and may be fewer although perhaps less constrained in values than indicators that are useful for detecting ecosystem collapse (or severe degradation). Finally, for provision of efficient management tools to implement EBFM, the robustness to environmental variability of such ecosystem-based reference levels at MMSY remains to be assessed. To identify and refine reference levels for the suite of ecological indicators examined here, extensive model simulations are recommended of prospective fishing strategies that are being/may be considered by managers in the Southern Benguela to maximize sustainable catches under various climate scenarios.

\section{Acknowledgments}

This work is a contribution to the IndiSeas Working Group (www .indiseas . org). The authors would like to thank Laure Velez for helping with the MMSY algorithm. We would also like to thank the two anonymous reviewers for their useful comments on earlier versions of the manuscript. 


\section{${ }_{539} 7 \quad$ Funding}

F.B. was funded by the French-South African ICEMASA program and Institut pour la Recherche et le Développement. L.J.S was funded by the Department of Science and Technology/National Research Foundation South African Research Chair in Marine Ecology and Fisheries, and Institut pour la Recherche et le Développement. Y.J.S and P.V. were partly funded by the Fondation pour la Recherche sur la Biodiversité [APPSCEN-2010-II]. 


\section{References}

Agnew, D.J., Pearce, J., Pramod, G., Peatman, T., Watson, R., Beddington, J.R., Pitcher, T.J., 2009. Estimating the Worldwide Extent of Illegal Fishing. PLoS ONE 4, e4570. URL: https://dx.plos.org/10.1371/journal .pone.0004570, doi:10.1371/ journal.pone.0004570.

Blanchard, J.L., Coll, M., Trenkel, V.M., Vergnon, R., Yemane, D., Jouffre, D., Link, J.S., Shin, Y.J., 2010. Trend analysis of indicators: a comparison of recent changes in the status of marine ecosystems around the world. ICES Journal of Marine Science 67, 732-744. URL: https://academic.oup.com/icesjms/article-lookup/doi/10. 1093/icesjms/fsp282, doi/10.1093/icesjms/fsp282.

Bland, L.M., Watermeyer, K.E., Keith, D.A., Nicholson, E., Regan, T.J., Shannon, L.J., 2018. Assessing risks to marine ecosystems with indicators, ecosystem models and experts. Biological Conservation 227, 19-28. URL: https://linkinghub.elsevier. com/retrieve/pii/S000632071731501X, doi:10.1016/j.biocon.2018.08.019

Branch, T.A., Watson, R., Fulton, E.A., Jennings, S., McGilliard, C.R., Pablico, G.T., Ricard, D., Tracey, S.R., 2010. The trophic fingerprint of marine fisheries. Nature 468, 431-435. URL: http://www. nature.com/doifinder/10.1038/nature09528, doi:10. 1038/nature09528.

Cheung, W., Watson, R., Morato, T., Pitcher, T., Pauly, D., 2007. Intrinsic vulnerability in the global fish catch. Marine Ecology Progress Series 333, 1-12. URL: http: //www.int-res.com/abstracts/meps/v333/p1-12/, doi:10.3354/meps333001.

Coll, M., Shannon, L., Kleisner, K., Juan-Jordá, M., Bundy, A., Akoglu, A., Banaru, D., Boldt, J., Borges, M., Cook, A., Diallo, I., Fu, C., Fox, C., Gascuel, D., Gurney, L., Hattab, T., Heymans, J., Jouffre, D., Knight, B., Kucukavsar, S., Large, S., Lynam, C., Machias, A., Marshall, K., Masski, H., Ojaveer, H., Piroddi, C., Tam, J., Thiao, D., Thiaw, M., Torres, M., Travers-Trolet, M., Tsagarakis, K., Tuck, I., van der Meeren, G., Yemane, D., Zador, S., Shin, Y.J., 2016. Ecological indicators to capture the effects of fishing on biodiversity and conservation status of marine ecosystems. Ecological Indicators 60, 947-962. URL: http://linkinghub.elsevier.com/retrieve/pii/ S1470160X1500480X, doi:10.1016/j.ecolind.2015.08.048.

Coll, M., Shannon, L.J., Yemane, D., Link, J.S., Ojaveer, H., Neira, S., Jouffre, D., Labrosse, P., Heymans, J.J., Fulton, E.A., Shin, Y.J., 2010. Ranking the ecological relative status of exploited marine ecosystems. ICES Journal of Marine Science 67, 769-786. URL: https://academic.oup.com/icesjms/article-lookup/doi/10. 1093/icesjms/fsp261, doi:10.1093/icesjms/fsp261.

Cury, P., Shannon, L., 2004. Regime shifts in upwelling ecosystems: observed changes and possible mechanisms in the northern and southern Benguela. Progress in Oceanography 60, 223-243. URL: http://linkinghub.elsevier.com/retrieve/ pii/S0079661104000291, doi:10.1016/j.pocean.2004.02.007.

Duboz, R., Versmisse, D., Travers, M., Ramat, E., Shin, Y.J., 2010. Application of an evolutionary algorithm to the inverse parameter estimation of an individual-based 
model. Ecological Modelling 221, 840-849. URL: http://linkinghub.elsevier. com/retrieve/pii/S0304380009008102, doi:10.1016/j .ecolmodel.2009.11.023.

Fogarty, M.J., 2014. The art of ecosystem-based fishery management. Canadian Journal of Fisheries and Aquatic Sciences 71, 479-490. URL: http:// www.nrcresearchpress.com/doi/10.1139/cjfas-2013-0203, doi:10.1139/cjfas2013-0203.

Fu, C., Large, S., Knight, B., Richardson, A.J., Bundy, A., Reygondeau, G., Boldt, J., van der Meeren, G.I., Torres, M.A., Sobrino, I., Auber, A., Travers-Trolet, M., Piroddi, C., Diallo, I., Jouffre, D., Mendes, H., Borges, M.F., Lynam, C.P., Coll, M., Shannon, L.J., Shin, Y.J., 2015. Relationships among fisheries exploitation, environmental conditions, and ecological indicators across a series of marine ecosystems. Journal of Marine Systems 148, 101-111. URL: http://linkinghub.elsevier.com/retrieve/ pii/S0924796315000160, doi:10.1016/j.jmarsys.2015.01.004.

Fu, C., Travers-Trolet, M., Velez, L., Grüss, A., Bundy, A., Shannon, L.J., Fulton, E.A., Akoglu, E., Houle, J.E., Coll, M., Verley, P., Heymans, J.J., John, E., Shin, Y.J., 2018. Risky business: The combined effects of fishing and changes in primary productivity on fish communities. Ecological Modelling 368, 265276. URL: http://linkinghub.elsevier.com/retrieve/pii/S0304380017302661, doi:10.1016/j.ecolmodel.2017.12.003.

Ghosh, B., Kar, T., 2013. Possible ecosystem impacts of applying maximum sustainable yield policy in food chain models. Journal of Theoretical Biology 329, 6-14. URL: http://linkinghub.elsevier.com/retrieve/pii/S0022519313001185, doi:10.1016/j.jtbi.2013.03.014.

Greenstreet, S.P.R., Rogers, S.I., Rice, J.C., Piet, G.J., Guirey, E.J., Fraser, H.M., Fryer, R.J., 2011. Development of the EcoQO for the North Sea fish community. ICES Journal of Marine Science 68, 1-11. URL: https://academic.oup.com/icesjms/ article-lookup/doi/10.1093/icesjms/fsq156, doi:10.1093/icesjms/fsq156.

Grüss, A., Schirripa, M.J., Chagaris, D., Velez, L., Shin, Y.J., Verley, P., OliverosRamos, R., Ainsworth, C.H., 2016. Estimating natural mortality rates and simulating fishing scenarios for Gulf of Mexico red grouper (Epinephelus morio) using the ecosystem model OSMOSE-WFS. Journal of Marine Systems 154, 264279. URL: http://linkinghub.elsevier.com/retrieve/pii/S0924796315001815, doi:10.1016/j.jmarsys.2015.10.014.

Hall, S.J., Mainprize, B., 2004. Towards ecosystem-based fisheries management. Fish and Fisheries 5, 1-20. URL: http://doi.wiley.com/10.1111/j.1467-2960.2004. 00133.x, doi:10.1111/j.1467-2960.2004.00133.x.

Jarre, A., Shannon, L., Cooper, R., Duggan, G., Gammage, L., Lockerbie, E., McGregor, E., Ragaller, S., Visser, N., Ward, C., Watermeyer, K., Weller, F., Ommer, R., 2018. Untangling a Gordian knot that must not be cut: Social-ecological systems research for management of southern Benguela fisheries. Journal of Marine Systems URL: http://linkinghub.elsevier.com/retrieve/pii/S0924796317300313, doi:10.1016/j.jmarsys.2018.01.004. 
Jennings, S., Collingridge, K., 2015. Predicting Consumer Biomass, Size-Structure, Production, Catch Potential, Responses to Fishing and Associated Uncertainties in the World's Marine Ecosystems. PLOS ONE 10, e0133794. URL: https://dx.plos. org/10.1371/journal.pone.0133794, doi:10.1371/journal.pone.0133794

Jennings, S., Dulvy, N., 2005. Reference points and reference directions for sizebased indicators of community structure. ICES Journal of Marine Science 62, 397404. URL: http://icesjms.oxfordjournals.org/cgi/doi/10.1016/j.icesjms. 2004.07 .030 , doi:10.1016/j.icesjms.2004.07.030.

Jennings, S., Greenstreet, S.P.R., Reynolds, J.D., 1999. Structural change in an exploited fish community: a consequence of differential fishing effects on species with contrasting life histories. Journal of Animal Ecology 68, 617-627. URL: http://doi. wiley.com/10.1046/j.1365-2656.1999.00312.x doi:10.1046/j.1365-2656.1999. 00312.x.

Keith, D.A., Rodríguez, J.P., Rodríguez-Clark, K.M., Nicholson, E., Aapala, K., Alonso, A., Asmussen, M., Bachman, S., Basset, A., Barrow, E.G., Benson, J.S., Bishop, M.J., Bonifacio, R., Brooks, T.M., Burgman, M.A., Comer, P., Comín, F.A., Essl, F., Faber-Langendoen, D., Fairweather, P.G., Holdaway, R.J., Jennings, M., Kingsford, R.T., Lester, R.E., Nally, R.M., McCarthy, M.A., Moat, J., Oliveira-Miranda, M.A., Pisanu, P., Poulin, B., Regan, T.J., Riecken, U., Spalding, M.D., ZambranoMartínez, S., 2013. Scientific Foundations for an IUCN Red List of Ecosystems. PLoS ONE 8, e62111. URL: http://dx.plos.org/10.1371/journal . pone.0062111. doi:10.1371/journal.pone.0062111.

Kolding, J., Jacobsen, N.S., Andersen, K.H., van Zwieten, P.A., Giacomini, H., 2016. Maximizing fisheries yields while maintaining community structure ${ }^{1}$. Canadian Journal of Fisheries and Aquatic Sciences 73, 644-655. URL: http:// www.nrcresearchpress.com/doi/10.1139/cjfas-2015-0098, doi:10.1139/cjfas2015-0098.

Koné, V., Machu, E., Penven, P., Andersen, V., Garçon, V., Fréon, P., Demarcq, H., 2005. Modeling the primary and secondary productions of the southern Benguela upwelling system: A comparative study through two biogeochemical models: SOUTHERN BENGUELA ECOSYSTEM MODELING. Global Biogeochemical Cycles 19, n/a-n/a. URL: http://doi.wiley.com/10.1029/2004GB002427, doi:10. 1029/2004GB002427.

Large, S., Fay, G., Friedland, K., Link, J., 2015. Critical points in ecosystem responses to fishing and environmental pressures. Marine Ecology Progress Series 521, 117. URL: http://www.int-res.com/abstracts/meps/v521/p1-17/, doi:10.3354/ meps 11165

Link, J.S., 2018. System-level optimal yield: increased value, less risk, improved stability, and better fisheries. Canadian Journal of Fisheries and Aquatic Sciences 75, 1-16. URL: http://www.nrcresearchpress.com/doi/10.1139/cjfas-2017-0250, doi:10.1139/cjfas-2017-0250.

Mackinson, S., Deas, B., Beveridge, D., Casey, J., 2009. Mixed-fishery or ecosystem conundrum? Multispecies considerations inform thinking on long-term management 
of North Sea demersal stocks. Canadian Journal of Fisheries and Aquatic Sciences 66, 1107-1129. URL: http://www.nrcresearchpress.com/doi/abs/10.1139/F09057, doi:10.1139/F09-057.

Marasco, R.J., Goodman, D., Grimes, C.B., Lawson, P.W., Punt, A.E., Quinn II, T.J., 2007. Ecosystem-based fisheries management: some practical suggestions. Canadian Journal of Fisheries and Aquatic Sciences 64, 928-939. URL: http://www. nrcresearchpress.com/doi/abs/10.1139/f07-062, doi:10.1139/f07-062

Moffitt, E.A., Punt, A.E., Holsman, K., Aydin, K.Y., Ianelli, J.N., Ortiz, I., 2016. Moving towards ecosystem-based fisheries management: Options for parameterizing multispecies biological reference points. Deep Sea Research Part II: Topical Studies in Oceanography 134, 350-359. URL: https://linkinghub. elsevier.com/retrieve/ pii/S0967064515002763, doi:10.1016/j.dsr2.2015.08.002.

Oliveros-Ramos, R., Shin, Y.J., 2016. calibraR: an R package for the calibration of individual based models. .

Rice, J., Rochet, M., 2005. A framework for selecting a suite of indicators for fisheries management. ICES Journal of Marine Science 62, 516-527. URL: http:// ices jms.oxfordjournals.org/cgi/doi/10.1016/j.icesjms.2005.01.003, doi:10. $1016 / j$.icesjms.2005.01.003.

Rindorf, A., Dichmont, C.M., Levin, P.S., Mace, P., Pascoe, S., Prellezo, R., Punt, A.E., Reid, D.G., Stephenson, R., Ulrich, C., Vinther, M., Clausen, L.W., 2016. Food for thought: pretty good multispecies yield. ICES Journal of Marine Science: Journal du Conseil , fsw071URL: https://academic.oup.com/icesjms/article-lookup/doi/ 10.1093/icesjms/fsw071, doi:10.1093/icesjms/fsw071

Ruckelshaus, M., Klinger, T., Knowlton, N., DeMASTER, D.P., 2008. Marine Ecosystem-based Management in Practice: Scientific and Governance Challenges. BioScience 58, 53. URL: http://bioscience.oxfordjournals.org/cgi/doi/10. 1641/B580110, doi:10.1641/B580110.

Shannon, L., Coll, M., Bundy, A., Gascuel, D., Heymans, J., Kleisner, K., Lynam, C., Piroddi, C., Tam, J., Travers-Trolet, M., Shin, Y., 2014. Trophic level-based indicators to track fishing impacts across marine ecosystems. Marine Ecology Progress Series 512, 115-140. URL: http://www.int-res.com/abstracts/meps/v512/p115-140/. doi:10.3354/meps10821.

Shannon, L.J., Cochrane, K.L., Moloney, C.L., Fréon, P., 2004. Ecosystem approach to fisheries management in the southern Benguela: a workshop overview. African Journal of Marine Science 26, 1-8. URL: http://www .tandfonline.com/doi/abs/ 10.2989/18142320409504046, doi:10.2989/18142320409504046.

Shin, Y., Rochet, M., Jennings, S., Field, J., Gislason, H., 2005. Using size-based indicators to evaluate the ecosystem effects of fishing. ICES Journal of Marine Science 62, 384-396. URL: http://ices jms.oxfordjournals.org/cgi/doi/10.1016/ j.icesjms.2005.01.004, doi:10.1016/j.icesjms.2005.01.004. 
Shin, Y.J., Bundy, A., Shannon, L.J., Blanchard, J.L., Chuenpagdee, R., Coll, M., Knight, B., Lynam, C., Piet, G., Richardson, A.J., 2012. Global in scope and regionally rich: an IndiSeas workshop helps shape the future of marine ecosystem indicators. Reviews in Fish Biology and Fisheries 22, 835-845. URL: http://link.springer.com/10. 1007/s11160-012-9252-z, doi:10.1007/s11160-012-9252-z

Shin, Y.J., Bundy, A., Shannon, L.J., Simier, M., Coll, M., Fulton, E.A., Link, J.S., Jouffre, D., Ojaveer, H., Mackinson, S., Heymans, J.J., Raid, T., 2010a. Can simple be useful and reliable? Using ecological indicators to represent and compare the states of marine ecosystems. ICES Journal of Marine Science 67, 717-731. URL: http://icesjms.oxfordjournals.org/cgi/doi/10.1093/icesjms/fsp287, doi:10. 1093/icesjms/fsp287.

Shin, Y.J., Cury, P., 2004. Using an individual-based model of fish assemblages to study the response of size spectra to changes in fishing. Canadian Journal of Fisheries and Aquatic Sciences 61, 414-431. URL: http://www.nrcresearchpress . com/doi/abs/ 10.1139/f03-154, doi:10.1139/f03-154.

Shin, Y.J., Houle, J.E., Akoglu, E., Blanchard, J.L., Bundy, A., Coll, M., Demarcq, H., Fu, C., Fulton, E.A., Heymans, J.J., Salihoglu, B., Shannon, L., Sporcic, M., Velez, L., 2018. The specificity of marine ecological indicators to fishing in the face of environmental change: A multi-model evaluation. Ecological Indicators 89, 317326. URL: http://linkinghub.elsevier.com/retrieve/pii/S1470160X18300104, doi:10.1016/j.ecolind.2018.01.010.

Shin, Y.J., Shannon, L.J., Bundy, A., Coll, M., Aydin, K., Bez, N., Blanchard, J.L., Borges, M.d.F., Diallo, I., Diaz, E., Heymans, J.J., Hill, L., Johannesen, E., Jouffre, D., Kifani, S., Labrosse, P., Link, J.S., Mackinson, S., Masski, H., Mollmann, C., Neira, S., Ojaveer, H., ould Mohammed Abdallahi, K., Perry, I., Thiao, D., Yemane, D., Cury, P.M., 2010b. Using indicators for evaluating, comparing, and communicating the ecological status of exploited marine ecosystems. 2. Setting the scene. ICES Journal of Marine Science 67, 692-716. URL: http://icesjms.oxfordjournals.org/cgi/ doi/10.1093/icesjms/fsp294, doi:10.1093/icesjms/fsp294.

Shin, Y.J., Shannon, L.J., Cury, P.M., 2004. Simulations of fishing effects on the southern Benguela fish community using an individual-based model: learning from a comparison with ECOSIM. African Journal of Marine Science 26, 95114. URL: http://www.tandfonline.com/doi/abs/10.2989/18142320409504052, doi:10.2989/18142320409504052.

Travers, M., Shin, Y.J., Jennings, S., Machu, E., Huggett, J., Field, J., Cury, P., 2009. Two-way coupling versus one-way forcing of plankton and fish models to predict ecosystem changes in the Benguela. Ecological Modelling 220, 30893099. URL: http://linkinghub.elsevier.com/retrieve/pii/S0304380009005766, doi:10.1016/j.ecolmodel.2009.08.016.

Travers, M., Shin, Y.J., Shannon, L., Cury, P., 2006. Simulating and testing the sensitivity of ecosystem-based indicators to fishing in the southern Benguela ecosystem. Canadian Journal of Fisheries and Aquatic Sciences 63, 943-956. URL: http: //www.nrcresearchpress.com/doi/abs/10.1139/f06-003, doi:10.1139/f06-003. 
Travers, M., Watermeyer, K., Shannon, L., Shin, Y.J., 2010. Changes in food web structure under scenarios of overfishing in the southern Benguela: Comparison of the Ecosim and OSMOSE modelling approaches. Journal of Marine Systems 79, 101111. URL: http://linkinghub.elsevier.com/retrieve/pii/S0924796309002346, doi:10.1016/j.jmarsys.2009.07.005

Travers-Trolet, M., Shin, Y.J., Field, J., 2014a. An end-to-end coupled model ROMS-N ${ }_{2} \mathrm{P}_{2} \mathrm{Z}_{2} \mathrm{D}_{2}$-OSMOSE of the southern Benguela foodweb: parameterisation, calibration and pattern-oriented validation. African Journal of Marine Science 36, 1129. URL: http://www . tandfonline.com/doi/abs/10.2989/1814232X.2014.883326, doi:10.2989/1814232X.2014.883326.

Travers-Trolet, M., Shin, Y.J., Shannon, L.J., Moloney, C.L., Field, J.G., 2014b. Combined Fishing and Climate Forcing in the Southern Benguela Upwelling Ecosystem: An End-to-End Modelling Approach Reveals Dampened Effects. PLoS ONE 9, e94286. URL: http://dx.plos.org/10.1371/journal.pone.0094286, doi:10.1371/ journal.pone.0094286.

Tromeur, E., Doyen, L., 2018. Optimal Harvesting Policies Threaten Biodiversity in Mixed Fisheries. Environmental Modeling \& Assessment URL: http://link. springer.com/10.1007/s10666-018-9618-2, doi:10.1007/s10666-018-9618-2.

Voss, R., Quaas, M., Schmidt, J., Hoffmann, J., 2014. Regional trade-offs from multispecies maximum sustainable yield (MMSY) management options. Marine Ecology Progress Series 498, 1-12. URL: http://www.int-res.com/abstracts/meps/v498/ p1-12/, doi:10.3354/meps10639.

Walters, C., Christensen, V., Martell, S., Kitchell, J., 2005. Possible ecosystem impacts of applying MSY policies from single-species assessment. ICES Journal of Marine Science 62, 558-568. URL: https://academic.oup.com/icesjms/article-lookup/ doi/10.1016/j.icesjms.2004.12.005, doi $10.1016 /$ j.icesjms. 2004.12 .005

Watermeyer, K.E., Hutchings, L., Jarre, A., Shannon, L.J., 2016. Patterns of Distribution and Spatial Indicators of Ecosystem Change Based on Key Species in the Southern Benguela. PLOS ONE 11, e0158734. URL: http://dx.plos.org/10.1371/journal. pone.0158734, doi:10.1371/journal.pone.0158734.

Worm, B., Hilborn, R., Baum, J.K., Branch, T.A., Collie, J.S., Costello, C., Fogarty, M.J., Fulton, E.A., Hutchings, J.A., Jennings, S., Jensen, O.P., Lotze, H.K., Mace, P.M., McClanahan, T.R., Minto, C., Palumbi, S.R., Parma, A.M., Ricard, D., Rosenberg, A.A., Watson, R., Zeller, D., 2009. Rebuilding Global Fisheries. Science 325, 578-585. URL: http://www.sciencemag.org/cgi/doi/10.1126/science.1173146, doi:10.1126/science.1173146. 
Table S1: Osmose species' parameters. Highlighted in gray: parameters estimated by the calibration algorithm. More information on the parameters can be found on

$$
\text { http://www .osmose-model.org }
$$

\begin{tabular}{|c|c|c|c|c|c|c|c|c|c|c|}
\hline & Anchov & Euphaus & $\begin{array}{l}\text { Shallow } \\
\text { iidvater } \\
\text { hake }\end{array}$ & $\begin{array}{l}\text { Deep } \\
\text { water } \\
\text { hake }\end{array}$ & $\begin{array}{c}\text { Horse } \\
\text { mack- } \\
\text { erel }\end{array}$ & $\begin{array}{l}\text { Meso- } \\
\text { pelagics }\end{array}$ & Redeye & Sardine & $\begin{array}{l}\text { Large } \\
\text { pelag- } \\
\text { ics }\end{array}$ & Snoek \\
\hline $\begin{array}{l}\text { Egg size } \\
(\mathrm{cm})\end{array}$ & 0.1 & 0.1 & 0.1 & 0.1 & 0.1 & 0.1 & 0.1 & 0.1 & 0.1 & 0.1 \\
\hline $\begin{array}{l}\text { Egg weight } \\
(\mathrm{kg})\end{array}$ & $\begin{array}{c}\text { 5.39E- } \\
04\end{array}$ & $\begin{array}{c}\text { 5.39E- } \\
04\end{array}$ & $\begin{array}{c}\text { 5.39E- } \\
04\end{array}$ & $\begin{array}{c}\text { 5.39E- } \\
04\end{array}$ & $\begin{array}{c}\text { 5.39E- } \\
04\end{array}$ & $\begin{array}{c}\text { 5.39E- } \\
04\end{array}$ & $\begin{array}{c}\text { 5.39E- } \\
04\end{array}$ & $\begin{array}{c}\text { 5.39E- } \\
04\end{array}$ & $\begin{array}{c}\text { 5.39E- } \\
04\end{array}$ & $\begin{array}{c}5.39 \mathrm{E}- \\
04\end{array}$ \\
\hline $\begin{array}{l}\text { Length to } \\
\text { weight } \\
\text { allometric } \\
\text { power }\end{array}$ & 3 & 3.16 & 3.0425 & 2.9759 & 3 & 3 & 3 & 3 & 3 & 3 \\
\hline 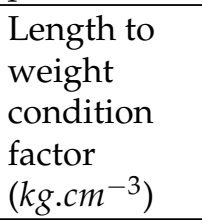 & 0.007 & 0.00738 & 0.00654 & 0.00785 & 0.009 & 0.008 & 0.009 & 0.009 & 0.007 & 0.018 \\
\hline $\begin{array}{l}\text { Lifespan } \\
(\mathrm{yr})\end{array}$ & 5 & 1 & 15 & 15 & 8 & 2 & 6 & 10 & 25 & 10 \\
\hline $\begin{array}{l}\text { Maturity } \\
\text { age (yr) }\end{array}$ & 1 & - & 4 & 4 & 3 & 0.5 & 1 & - & 2 & - \\
\hline $\begin{array}{l}\text { Maturity } \\
\text { size }(\mathrm{cm})\end{array}$ & - & 1.05 & - & - & - & - & - & 18 & - & 73 \\
\hline $\begin{array}{l}\text { Relative } \\
\text { fecundity } \\
\text { (eggs/gram } \\
\text { of mature } \\
\text { female) }\end{array}$ & 8000 & 42254 & 500 & 500 & 250 & 646 & 750 & 2400 & 150 & 130 \\
\hline Sex ratio & 0.5 & 0.5 & 0.5 & 0.5 & 0.5 & 0.5 & 0.5 & 0.5 & 0.5 & 0.5 \\
\hline $\mathrm{K}\left(y r^{-1}\right)$ & 1.37 & 1.682 & 0.039 & 0.049 & 0.183 & 1.66 & 0.71 & 0.26 & 0.12 & 0.294 \\
\hline$\underset{\Xi}{\Xi} L_{\infty}(\mathrm{cm})$ & 14.8 & 1.84 & 270.6 & 219.4 & 54.5 & 7 & 30.1 & 26 & 116 & 115.3 \\
\hline స్ّ & -0.03 & -0.198 & -0.73 & -0.914 & -0.65 & 0.06 & 0.28 & -1.5 & -1.47 & -0.01 \\
\hline 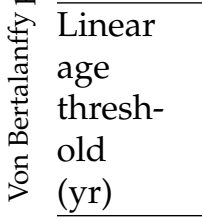 & 1 & 0.17 & 1 & 1 & 1 & 1 & 1 & 1 & 1 & 1 \\
\hline $\begin{array}{l}\text { Natural } \\
\text { mortality } \\
\text { rate }\left(y r^{-1}\right)\end{array}$ & 0.403 & 0.1 & 0.228 & 0.174 & 0.314 & 0.226 & 0.208 & 0.365 & 0.228 & 0.132 \\
\hline $\begin{array}{l}\text { Larval } \\
\text { natural } \\
\text { mortality } \\
\text { rate }\left(y r^{-1}\right)\end{array}$ & 6.191 & 5.305 & 4.669 & 4.404 & 4.547 & 4.358 & 5.706 & 3.119 & 7.874 & 10.456 \\
\hline $\begin{array}{l}\text { Predation } \\
\text { efficiency }\end{array}$ & 0.57 & 0.57 & 0.57 & 0.57 & 0.57 & 0.57 & 0.57 & 0.57 & 0.57 & 0.57 \\
\hline
\end{tabular}


Table S1 Continued:

\begin{tabular}{|c|c|c|c|c|c|c|c|c|c|c|}
\hline & Anchovy & Krill & $\begin{array}{c}\text { Shallow } \\
\text { water } \\
\text { hake }\end{array}$ & $\begin{array}{l}\text { Deep } \\
\text { water } \\
\text { hake }\end{array}$ & $\begin{array}{l}\text { Horse } \\
\text { mack- } \\
\text { erel }\end{array}$ & $\begin{array}{l}\text { Meso- } \\
\text { pelagics }\end{array}$ & Redeye & Sardine & $\begin{array}{l}\text { Large } \\
\text { pelag- } \\
\text { ics }\end{array}$ & Snoek \\
\hline $\begin{array}{l}\text { Max in- } \\
\text { gestion rate } \\
\left(g \cdot g^{-1} \cdot y r^{-1}\right)\end{array}$ & 3.5 & 3.5 & 3.22 & 3.15 & 3.5 & 3.5 & 3.5 & 3.5 & 2.7 & 3.15 \\
\hline $\begin{array}{l}\text { Pred-prey size } \\
\text { ratio max }\end{array}$ & 10 & 15 & 3.5 & 3.5 & 10 & 2.5 & 10 & 100 & 3.5 & \multirow[t]{2}{*}{$\begin{array}{c}3.5 \\
-\end{array}$} \\
\hline $\begin{array}{l}\text { (before/after } \\
\text { threshold) }\end{array}$ & 5 & 5 & 1.8 & 1.8 & 5 & - & - & 200 & - & \\
\hline $\begin{array}{l}\text { Pred-prey size } \\
\text { ratio min }\end{array}$ & 100 & 300 & 50 & 50 & 100 & 100 & 100 & 200 & 70 & \multirow[t]{2}{*}{$\begin{array}{c}70 \\
-\end{array}$} \\
\hline $\begin{array}{l}\text { (before/after } \\
\text { threshold) }\end{array}$ & 500 & 100 & 50 & 50 & 100 & - & - & 400 & - & \\
\hline $\begin{array}{l}\text { Pred-prey } \\
\text { size } \\
\text { threshold } \\
(\mathrm{cm})\end{array}$ & 8 & 0.6 & 27 & 29 & 10 & - & - & 10 & - & - \\
\hline $\begin{array}{l}\text { Mortality } \\
\text { starvation } \\
\text { rate }\left(y r^{-1}\right)\end{array}$ & 3 & 3 & 3 & 3 & 3 & 3 & 3 & 3 & 3 & 3 \\
\hline $\begin{array}{l}\text { Current } \\
\text { fishing } \\
\text { mortality } \\
\text { rate }\left(y r^{-1}\right)\end{array}$ & 0.142 & 0 & 0.334 & 0.357 & 0.050 & 0.001 & 0.050 & 0.190 & 0.138 & 0.229 \\
\hline $\begin{array}{l}\text { Recruitment } \\
\text { age to the } \\
\text { fishery (yr) }\end{array}$ & 0.62 & 1 & 2.5 & 1.9 & 2 & 1 & 1 & 1 & 1 & 3 \\
\hline $\begin{array}{l}\mathrm{Nb} \text { of } \\
\text { schools }\end{array}$ & 24 & 100 & 24 & 24 & 24 & 100 & 24 & 24 & 24 & 24 \\
\hline
\end{tabular}

\begin{tabular}{lcccc}
\hline & Dinoflagellates & Diatoms & Ciliates & Copepods \\
\hline $\begin{array}{l}\text { Accessibility } \\
\text { to fish }\end{array}$ & 0.0269 & 0.0030 & 0.0142 & 0.1854 \\
\hline $\begin{array}{l}\text { Conversion } \\
\text { factor } \\
(\mathrm{mmol}\end{array}$ & 0.72 & 0.72 & 0.675 & 1 \\
$\begin{array}{l}N . m^{-2} \text { to } \\
\left.\text { ton. } \mathrm{km}^{-2}\right)\end{array}$ & 0.002 & 0.02 & 0.02 & 0.3 \\
\hline $\begin{array}{l}\text { Maximal } \\
\text { size }(\mathrm{cm})\end{array}$ & 0.0002 & 0.002 & 0.002 & 0.02 \\
\hline $\begin{array}{l}\text { Minimal } \\
\text { size }(\mathrm{cm})\end{array}$ & 1 & 1 & 2 & 2.5 \\
\hline TL & & & & \\
\hline
\end{tabular}


Table S2: Indicators' species parameters

\begin{tabular}{lccccccccccc}
\hline & Anchovy & Krill & $\begin{array}{c}\text { Shallow } \\
\text { water } \\
\text { hake }\end{array}$ & $\begin{array}{c}\text { Deep } \\
\text { water } \\
\text { hake }\end{array}$ & $\begin{array}{c}\text { Horse } \\
\text { mack- } \\
\text { erel }\end{array}$ & $\begin{array}{c}\text { Meso- } \\
\text { pelagics }\end{array}$ & Redeye & Sardine & $\begin{array}{c}\text { Large } \\
\text { pelag- } \\
\text { ics }\end{array}$ & Snoek \\
\hline Predator & No & No & Yes & Yes & No & No & No & No & Yes & Yes \\
\hline Surveyed & Yes & No & Yes & Yes & Yes & No & Yes & Yes & Yes & Yes \\
\hline Harvested & Yes & No & Yes & Yes & Yes & No & Yes & Yes & Yes & Yes \\
\hline Vulnerability & 44 & 1 & 59 & 59 & 44 & 31 & 46 & 54 & 60 & 61 \\
\hline
\end{tabular}

Surveyed species:

These are species sampled by researchers during routine surveys (as opposed to species sampled in catches by fishing vessels), and should include species of demersal and pelagic fish (bony and cartilaginous, small and large), as well as commercially important invertebrates (squids, crabs, shrimps...). Intertidal and subtidal crustaceans and molluscs such as abalones and mussels, mammalian and avian top predators, and turtles, should be excluded.

Predatory fish species:

Predatory fish are considered to be all surveyed fish species that are not largely planktivorous (i.e. phytoplankton and zooplankton feeders should be excluded). A fish species is classified as predatory if it is piscivorous, or if it feeds on invertebrates that are larger than the macrozooplankton category $(>2 \mathrm{~cm})$. Detritivores should not be classified as predatory fish.

Intrinsic Vulnerability:

The intrinsic vulnerability index of a species (IVIs) is based on life history traits and ecological characteristics, ranges from 0 to 100 , with 100 being the most vulnerable. For more details, see (Cheung et al., 2007). 


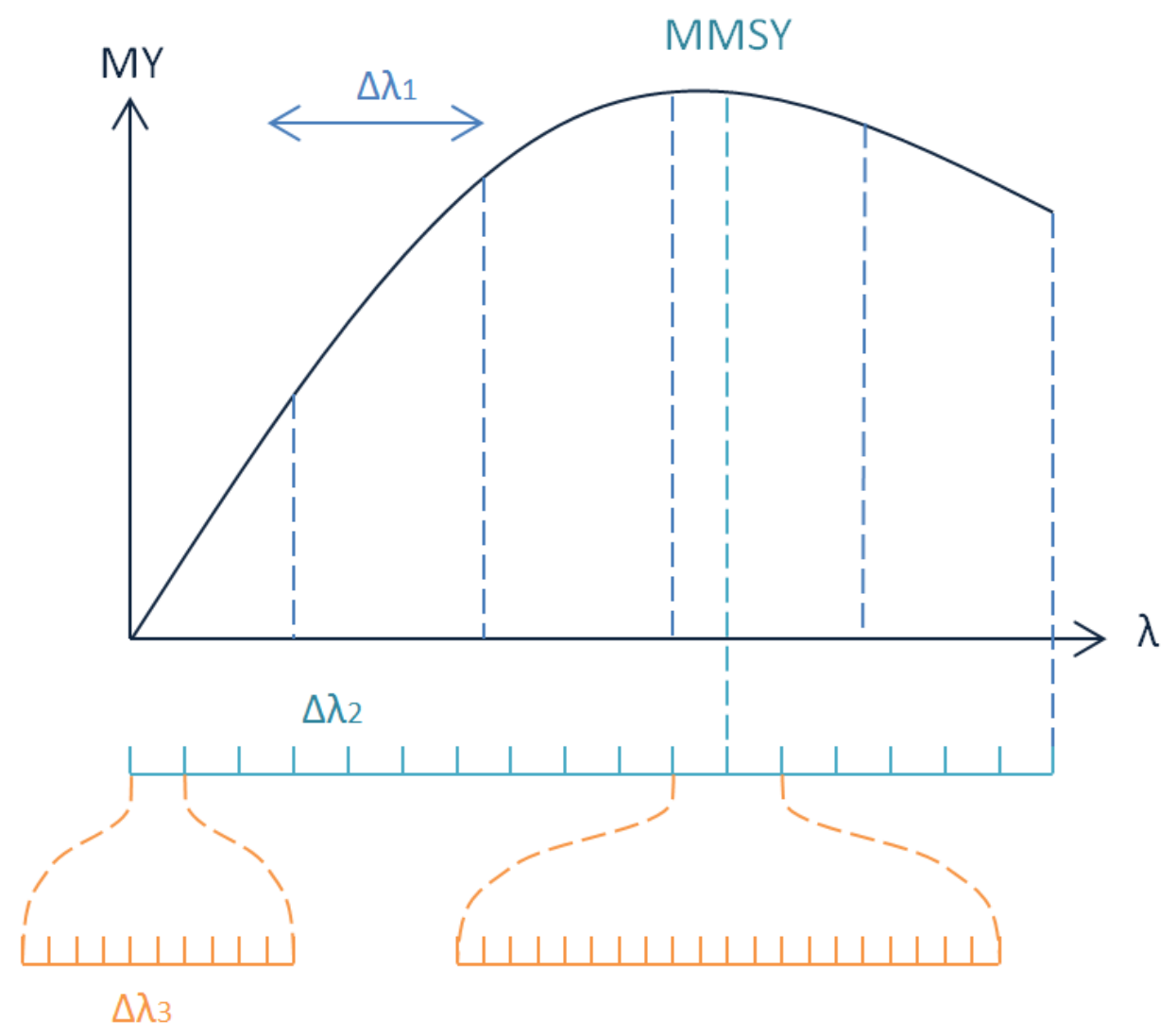

Figure S1: Illustration of the different phases of the algorithm for reaching the multispecies maximum sustainable yield (MMSY). For each fishing strategy, the step of the fishing mortality multiplier $\lambda$ is progressively refined from a coarse step $\left(\Delta \lambda_{1}\right)$ to the finest step $\left(\Delta \lambda_{3}\right)$ 

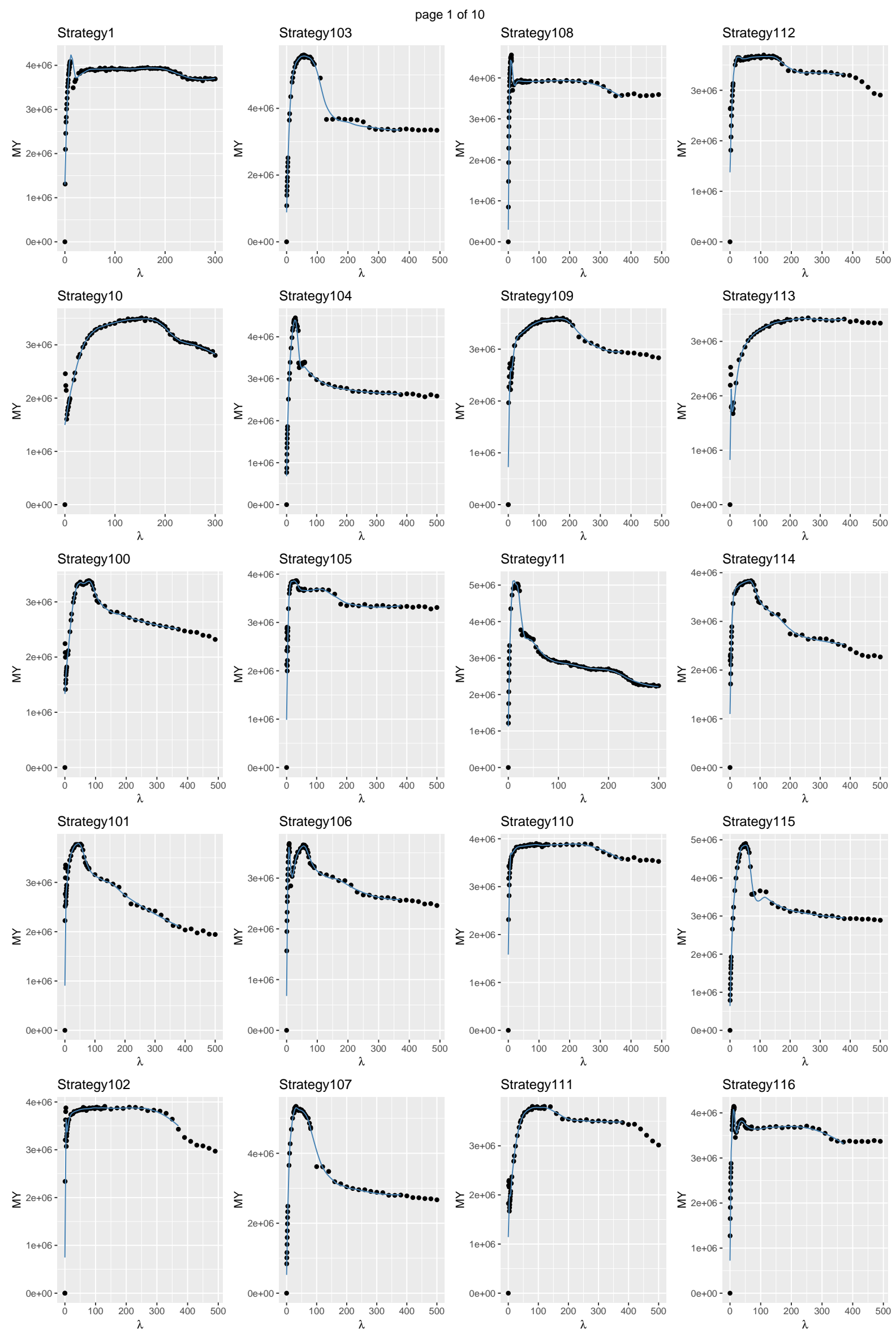

Figure S2: Evolution of multispecies yield with fishing pressure across all simulated fishing strategies. In many cases, the multispecies yield curve does not display the typical bell-shaped curve often presented (Worm et 37. 2009) but rather decreases very slowly once MMSY has been reached or level off to a plateau. 

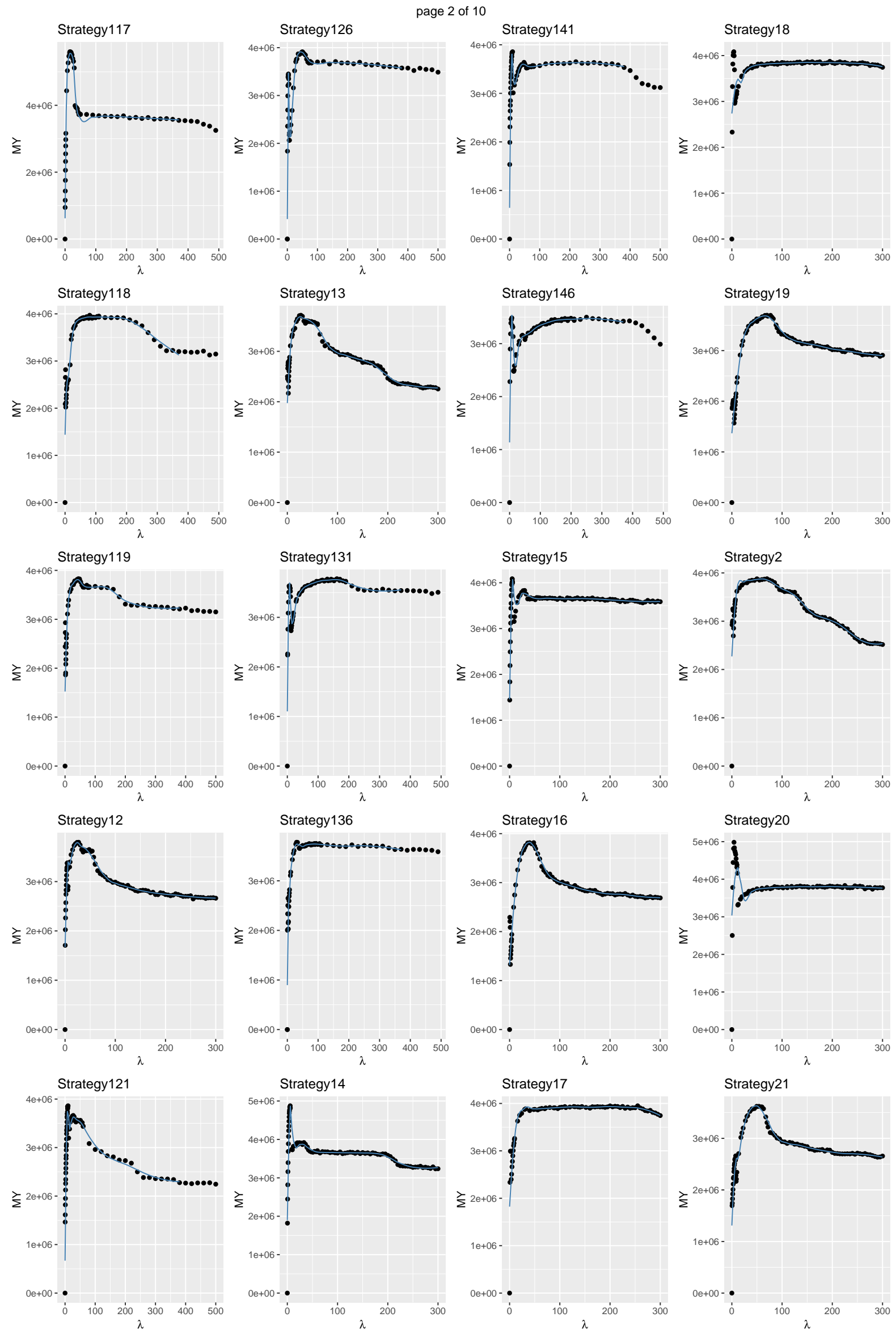

Figure S2: Evolution of multispecies yield with fishing pressure across all simulated fishing strategies. In many cases, the multispecies yield curve does not display the typical bell-shaped curve often presented (Worm et 38, 2009) but rather decreases very slowly once MMSY has been reached or level off to a plateau. 

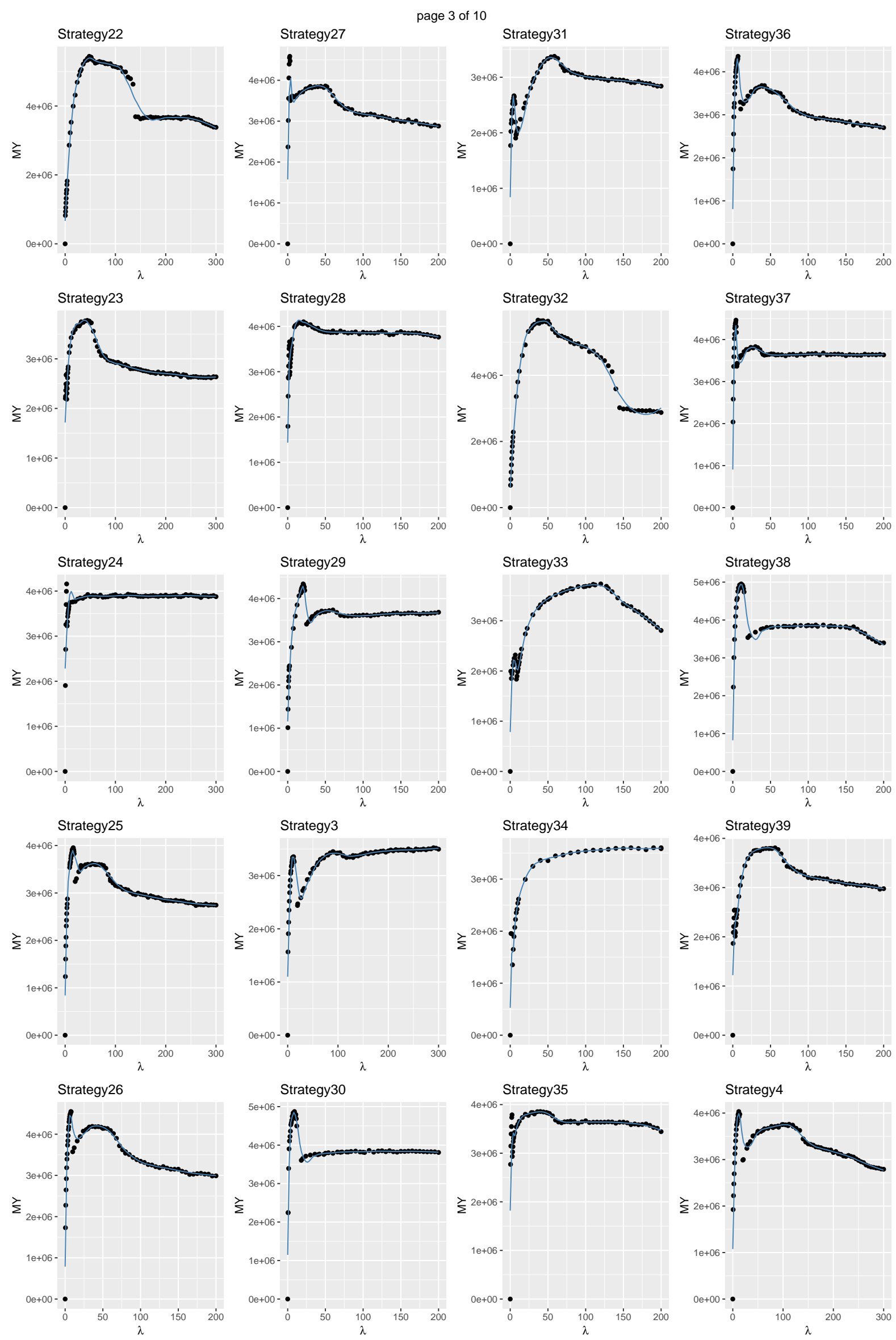

Figure S2: Evolution of multispecies yield with fishing pressure across all simulated fishing strategies. In many cases, the multispecies yield curve does not display the typical bell-shaped curve often presented (Worm et 39., 2009) but rather decreases very slowly once MMSY has been reached or level off to a plateau. 

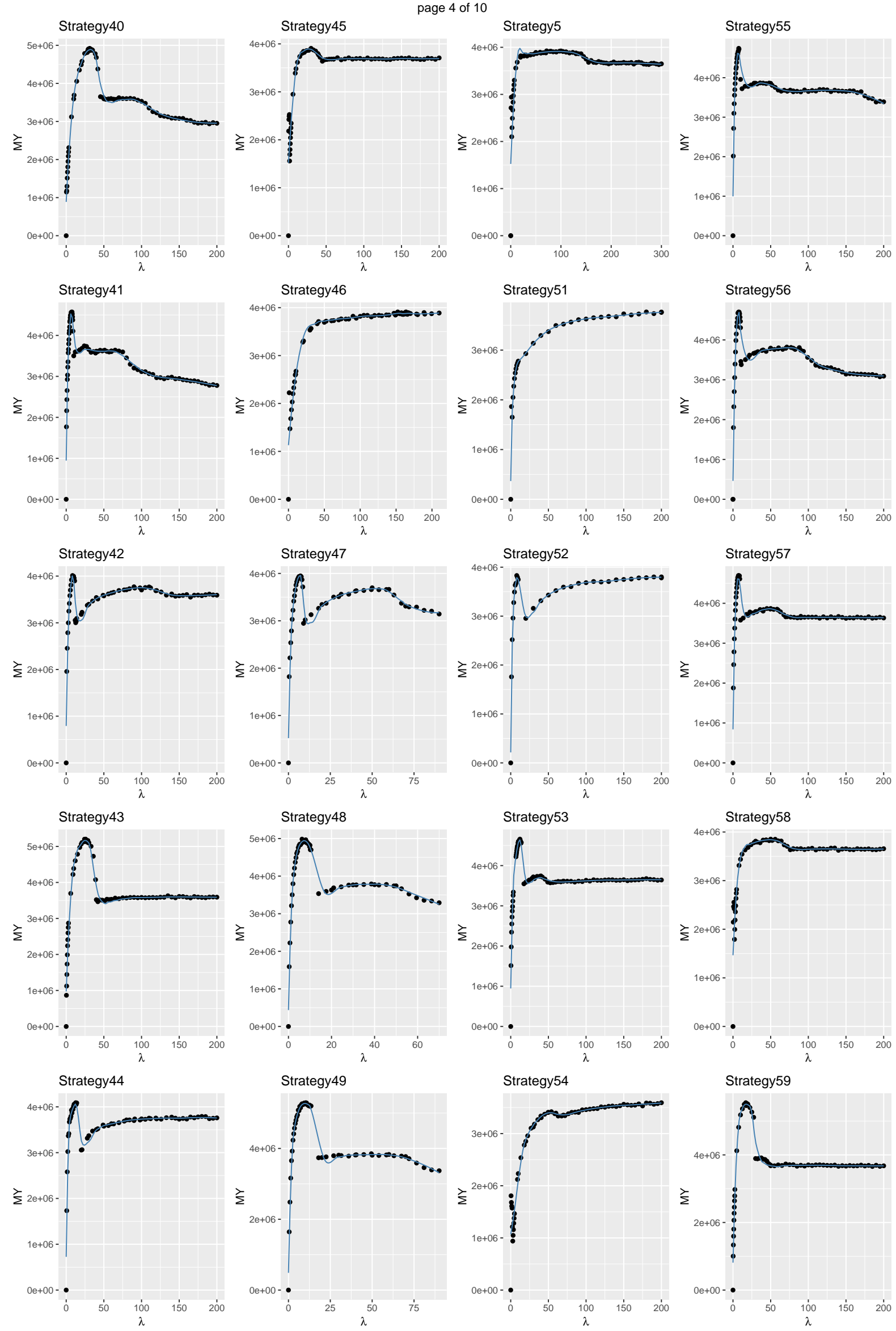

Figure S2: Evolution of multispecies yield with fishing pressure across all simulated fishing strategies. In many cases, the multispecies yield curve does not display the typical bell-shaped curve often presented (Worm et 40, 2009) but rather decreases very slowly once MMSY has been reached or level off to a plateau. 

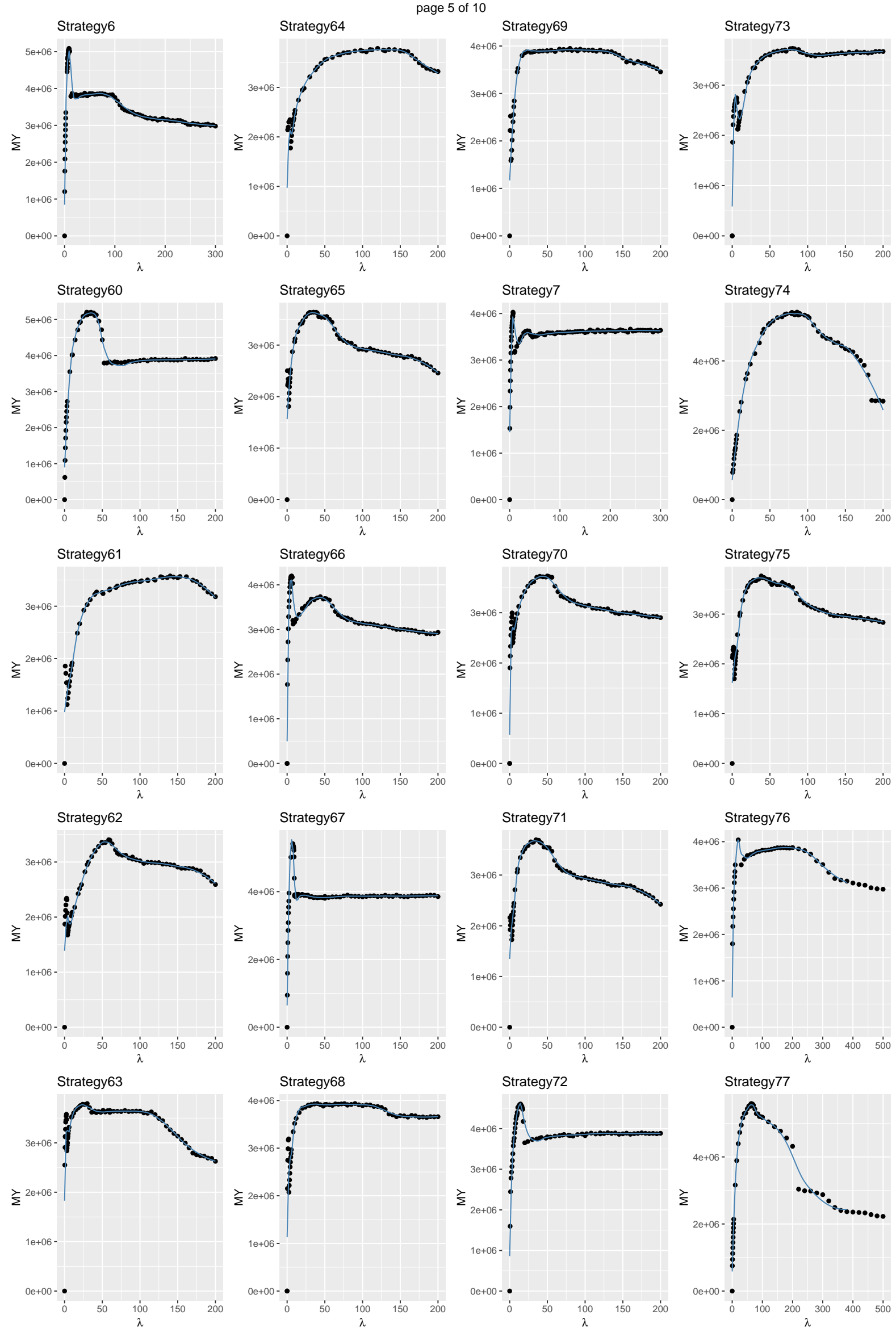

Figure S2: Evolution of multispecies yield with fishing pressure across all simulated fishing strategies. In many cases, the multispecies yield curve does not display the typical bell-shaped curve often presented (Worm et 41, 2009) but rather decreases very slowly once MMSY has been reached or level off to a plateau. 

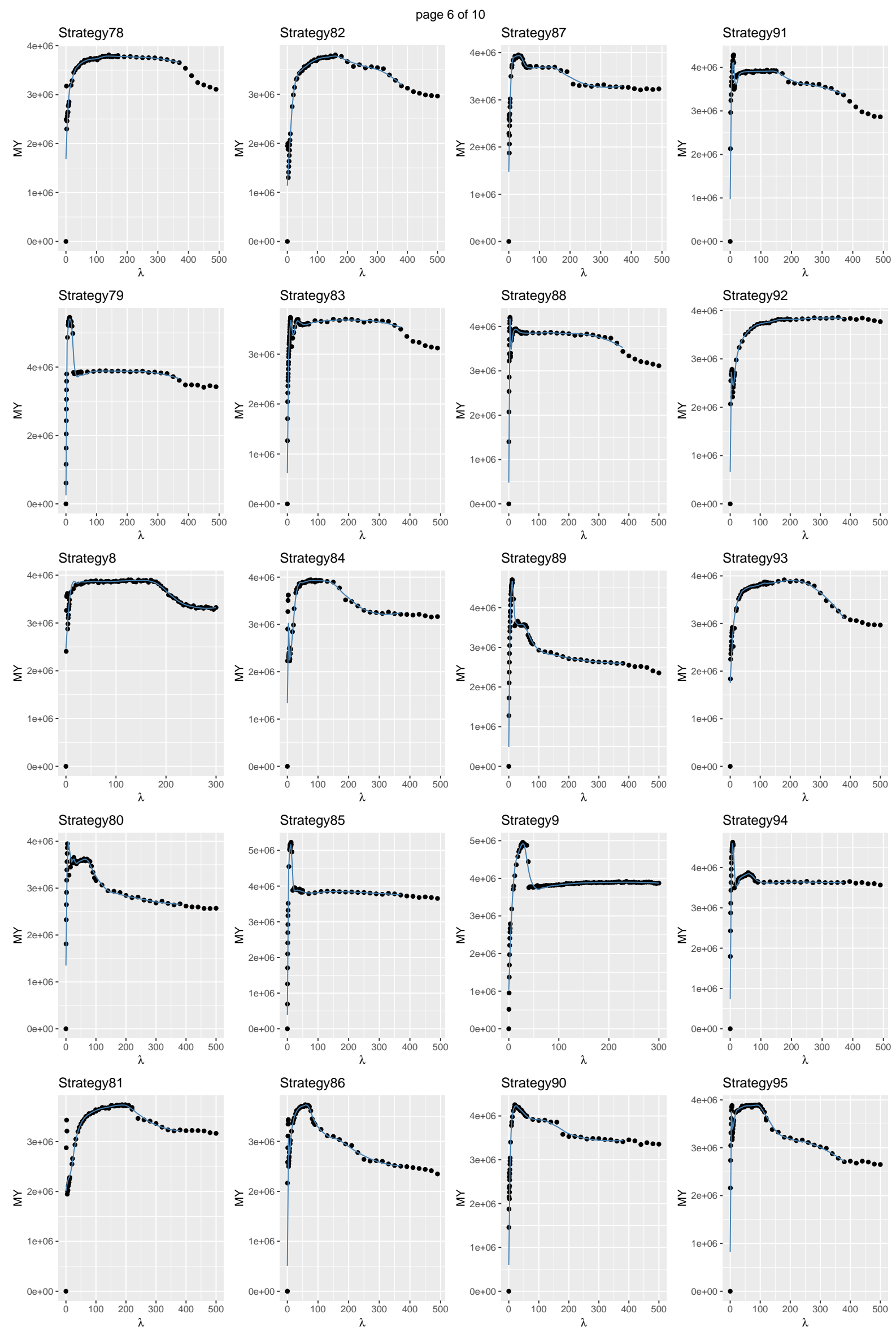

Figure S2: Evolution of multispecies yield with fishing pressure across all simulated fishing strategies. In many cases, the multispecies yield curve does not display the typical bell-shaped curve often presented (Worm et 4L, 2009) but rather decreases very slowly once MMSY has been reached or level off to a plateau. 

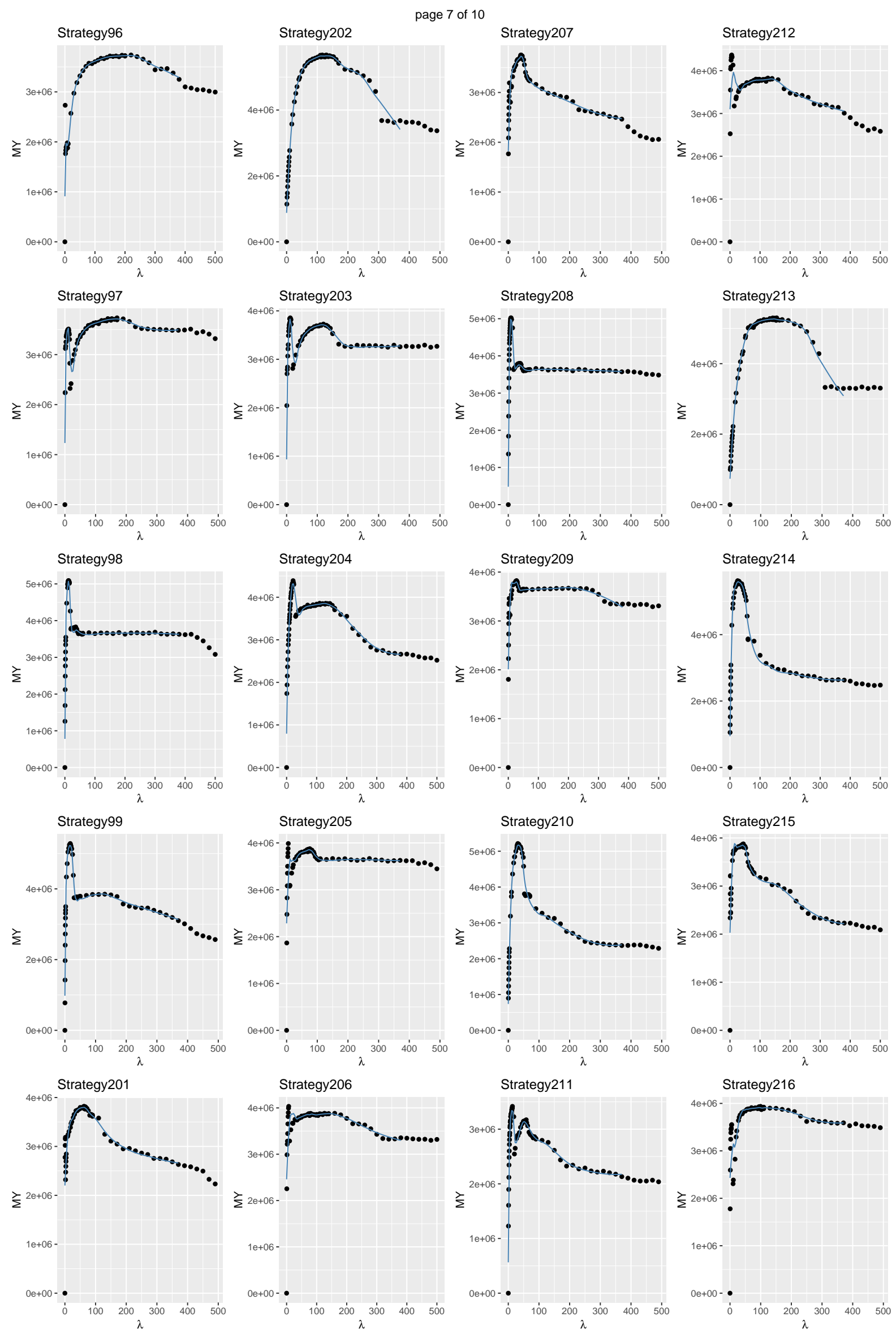

Figure S2: Evolution of multispecies yield with fishing pressure across all simulated fishing strategies. In many cases, the multispecies yield curve does not display the typical bell-shaped curve often presented (Worm et AB, 2009) but rather decreases very slowly once MMSY has been reached or level off to a plateau. 



Figure S2: Evolution of multispecies yield with fishing pressure across all simulated fishing strategies. In many cases, the multispecies yield curve does not display the typical bell-shaped curve often presented (Worm et 44t, 2009) but rather decreases very slowly once MMSY has been reached or level off to a plateau. 

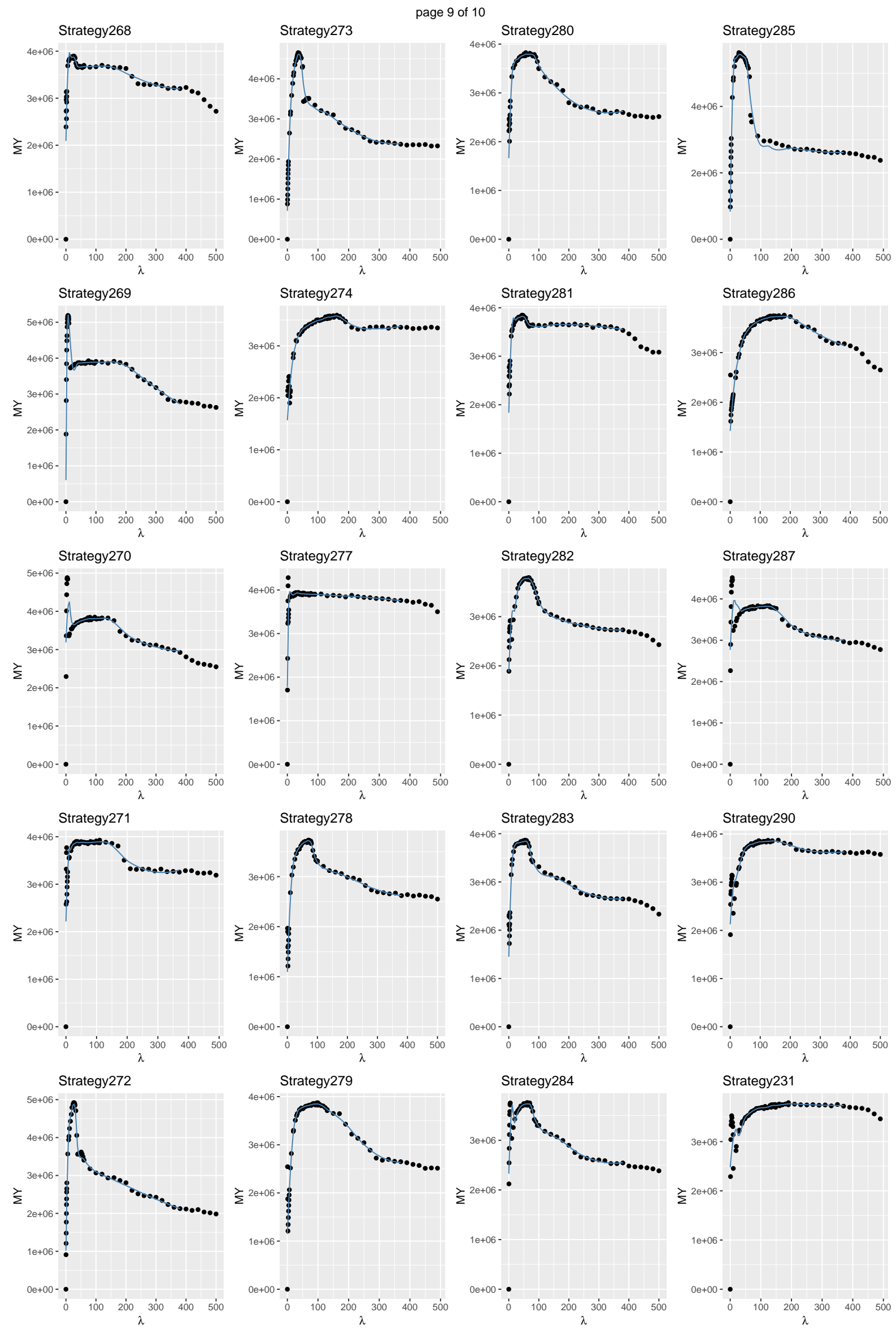

Figure S2: Evolution of multispecies yield with fishing pressure across all simulated fishing strategies. In many cases, the multispecies yield curve does not display the typical bell-shaped curve often presented (Worm et 45, 2009) but rather decreases very slowly once MMSY has been reached or level off to a plateau. 

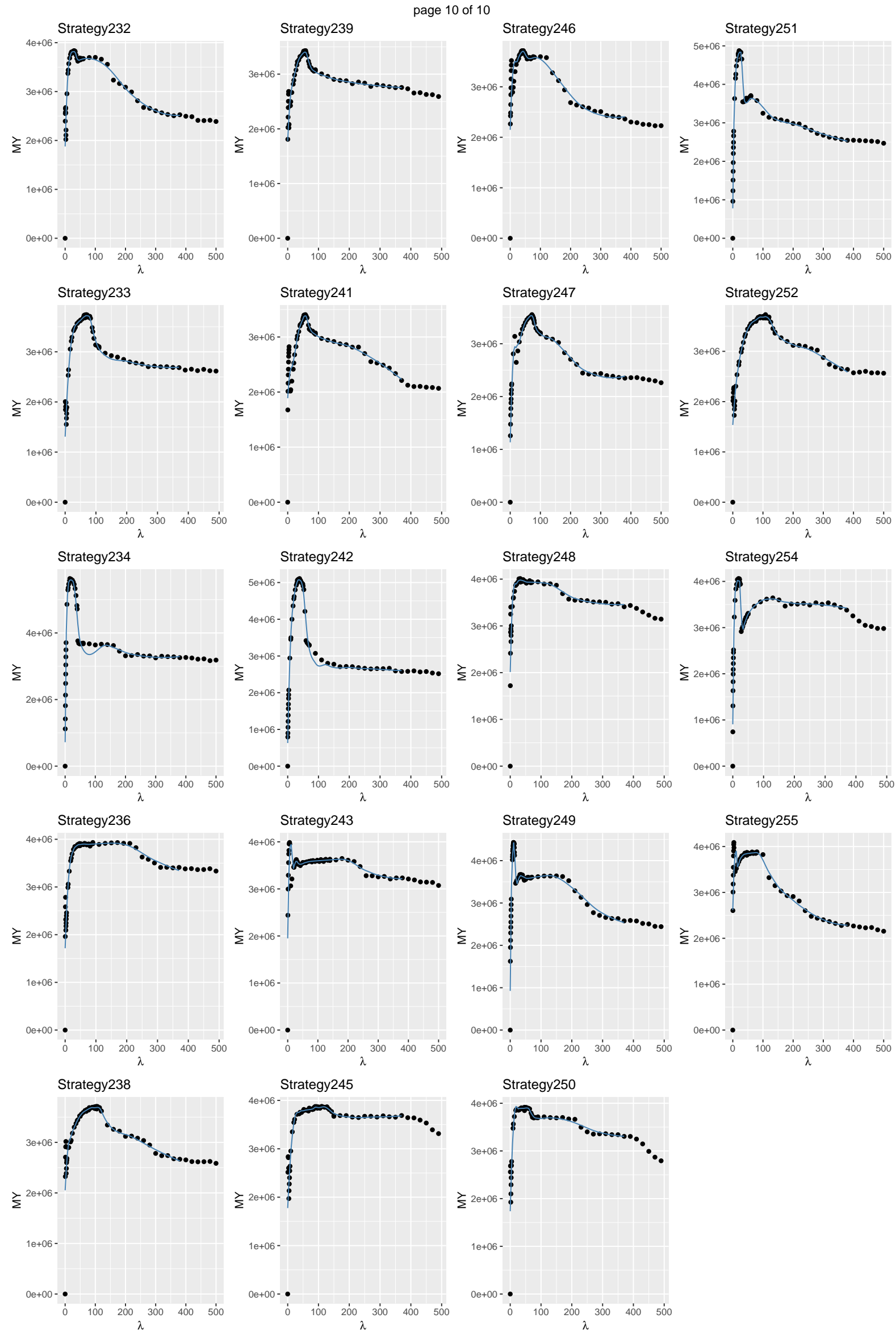

Figure S2: Evolution of multispecies yield with fishing pressure across all simulated fishing strategies. In many cases, the multispecies yield curve does not display the typical bell-shaped curve often presented (Worm et 46, 2009) but rather decreases very slowly once MMSY has been reached or level off to a plateau. 